\title{
Mística y parapsicología
}

\section{PRESENTACIÓN}

Desde hace varios siglos la teología espiritual se ha dividido en dos partes: ascética y mística. La mística era entendida según la doctrina propuesta por san Juan de la Cruz, tomando como base la experiencia de santa Teresa. La ascética era la preparación para la misma. Sobre estos dos polos ha girado toda la espiritualidad cristiana.

El P. Lope Cilleruelo (q.e.p.d.) tuvo el indiscutible mérito de descubrir otro modo de entender la mística basándose en san Agustín: era la mística de la Memoria Dei, que en vez de dirigirse por el camino de la experiencia teresiana miraba hacia lo eterno en el hombre. En esta concepción puramente cristiana y agustiniana los fenómenos místicos no tenían ningún papel, por lo que fueron considerados por el P. Lope como fenómenos naturales provenientes del inconsciente. Así pudo escribir en Estudio Agustiniano, 3 (1979), p. 439, un artículo titulado: «La mística de la Memoria Dei en San Agustín», en el que decía:

«La experiencia de los místicos obligó a los escolásticos a explicar la esencia del fenómeno místico como «contemplación infusa». Del mismo modo se impone hoy la identificación de esa contemplación infusa con la visión intelectual de san Agustín... nos referimos (en la contemplación infusa) a un fenómeno del inconsciente y hablamos de «pasividad», como en el caso de los impulsos, escrúpulos, ensueños, etc.»

Falta por realizar una espiritualidad cristiana que sea realmente evangélica y objetiva. Ésta es la siguiente:

1. ${ }^{\circ}$ El camino filosófico de la verdad. Consiste en buscar lo eterno en el hombre, tal como propone san Agustín en las Confesiones.

2. ${ }^{\circ}$ El camino teólógico de la verdad. Es identificar lo eterno en el hombre con Dios, que es la Verdad Suprema. Equivale a la mística de la Memoria Dei.

3. El camino cristiano de la verdad. Es identifiçar la verdad con Cristo, 
que es camino, verdad y vida. Se identifica con la mística específicamente cristiana.

La meta de la mística cristiana no es la unión con Dios, como propone san Juan de la Cruz, sino la transformación en Cristo. Lo primero es común a todas las místicas, lo segundo es sólo propio del cristianismo.

El camino de la mística cristiana no es la purificación, iluminación y la unión mística, sino la participación en el misterio pascual de Cristo. Lo primero es común al yoga, al neoplatonismo griego y a la mística clásica; sólo lo segundo es propio del cristianismo.

La fuerza para seguir el camino y alcanzar la meta no se basa en el esfuerzo humano, aunque sea con la ayuda de la gracia de Dios, sino en la acción dinámica del Espíritu Santo puesta de manifiesto a través de la fe. El esfuerzo humano aunque sea con la ayuda de la gracia de Dios es el cristianismo judaizante condenado por san Pablo en la carta a los Gálatas. Por el contrario, la salvación cristiana se basa sólo en la fe, aunque se trata de una fe viva que, con la fuerza dinámica del Espíritu Santo impulsa al hombre a la acción apostólica y a la vida de oración.

La importancia del presente trabajo estriba en que la espiritualidad cristiana ha dejado la oración profunda para la mística, y ha seguido una ascética de carácter oriental y judaizante demasiado centrada en el esfuerzo humano; la consecuencia es el fracaso actual de la vida religiosa. El verdadero camino es darle mucha importancia a la vida de oración, entendida como san Agustín y no como santa Teresa y san Juan de la Cruz, y vivir a fondo la fe para recibir la fuerza dinámica del Espíritu Santo y poder actuar después.

Si se considera conveniente publicar el presente artículo, en el que trato de desmitificar los fenómenos místicos, más adelante ofrecería otro desarrollando las ideas que aquí he sintetizado, pues las tengo ya muy elaboradas.

\section{MÍSTICA Y PARAPSICOLOGÍA I}

\section{LA EXPERIENCIA MÍSTICA}

La experiencia mística se refiere al conjunto de fenómenos atribuidos unánimemente a la acción sobre el alma de los dones del Espíritu Santo. Para conocerla hay que recurrir necesariamente a santa Teresa, maestra indiscutible en la descripción de la misma. Hay que estudiarla en función de su vida de oración, ya que fue apareciendo a medida que ésta se fue haciendo más intensa y profunda. Ahora bien, es preciso distinguir entre la oración ordinaria o ascética y la oración extraordinaria o mística, pues sólo en esta última apare- 
cen los fenómenos atribuidos a la acción divina sobre el alma. Entre ambas se encuentra la llamada «oración de recogimiento», que señala exactamente el paso de la una a la otra.

\section{LA ORACIÓN ORDINARIA}

La oración ordinaria corresponde a la etapa ascética de la vida espiritual. Está simbolizada por el primer modo de regar el huerto ${ }^{1}$, y corresponde a las tres primeras moradas del Castillo interior. Aparecen aquí dos formas de oración: la oración vocal y la meditación discursiva.

\section{La oración yocal}

La oración vocal es la que se realiza con fórmulas fijas, utilizando el lenguaje ordinario o haciéndolo mentalmente. Dentro de esta forma de estar con Dios hay muchas y muy buenas fórmulas, tales como el padrenuestro, el avemaría, la salve, etc. Con ellas se realiza la oración pública o litúrgica, que tanta importancia tiene para la vida de la Iglesia. Es absolutamente necesaria para orar en común.

La gran ventaja de la oración vocal es que resulta muy fácil de hacer, ya que consiste en la repetición de una misma fórmula aprendida de memoria, o la lectura de bellas expresiones como las de los salmos. Tiene el grave inconveniente de que, si no se pone especial cuidado, puede hacerse de manera rutinaria, con lo que deja de ser verdadera oración. Santa Teresa dice de ella que ya es oración mental, pero que es necesario rezar con advertencia, y entender y saber lo que se dice ${ }^{2}$.

Los directores espirituales consideran que quienes preferentemente han de servirse de la oración vocal son los principiantes, ya que no estando familiarizados con las altas actividades intelectuales necesitan de fórmulas para alimentar su pensamiento. Sin embargo, por muy elevados que estén los contemplativos en su oración silenciosa con Dios, nunca deben menospreciar esta forma de plegaria. Recurrir a ella es un ejercicio de humildad y sencillez muy provechoso para el alma.

La oración vocal, que para los autores espirituales constituye el primer grado de oración, tiene un alto valor si se sabe poner en ella el corazón. Santa Teresa lo dice de esta manera:

«Y porque no penséis se saca poca ganancia de rezar vocalmente con perfec-

1. Vida, 11,7.9.

2. Camino de perfección, 24,2 . 
ción, os digo que es muy posible que estando rezando el Paternóster os ponga el Señor en contemplación perfecta, o rezando otra oración vocal» ${ }^{3}$.

«Sé que muchas personas, rezando vocalmente, como ya queda dicho, las levanta Dios, sin entender ellas cómo, a subida contemplación. Conozco una persona que nunca pudo tener sino oración vocal, y asida a ésta lo tenía todo» ${ }^{4}$.

Rezando vocalmente es posible que el Señor eleve el alma hasta los estados pasivos, quietud y éxtasis, que se producen en la mística. Ahora bien, tanto si se entra en éxtasis como si se permanece en el estado ordinario, toda oración auténtica en la que se pone el corazón en Dios es de gran provecho para la vida espiritual.

\section{La meditación}

La meditación recibe generalmente el nombre de oración mental u oración discursiva. Consiste en la aplicación de la mente a las verdades sobrenaturales a través del razonamiento. Una forma muy corriente de hacer meditación consiste en tomar un libro apropiado, leerlo y reflexionar sobre él: es la «lectura reflexionada». Pero no debe ser una simple lectura espiritual, sino que hay que procurar participar activamente pensando reflexivamente en lo que dice, con objeto de convertirla en un ejercicio mental. Poco a poco se debe ir prescindiendo del libro para que la participación sea mayor.

De esta forma de orar dice santa Teresa que es la puerta del Castillo ${ }^{5}$. Tiene dos variedades: la meditación discursiva y la meditación simplificada:

Meditación discursiva. La forma más elemental de orar mentalmente se realiza reflexionando en lo que dice un libro. Santa Teresa tuvo que comenzar así ya que al principio no era capaz de orar de otro modo:

«Yo estuve más de catorce (años) que nunca podía tener aun meditación sino junto con lección» ${ }^{6}$.

«En todos éstos, si no era acabando de comulgar, jamás osaba comenzar a tener oración sin un libro; que, tanto temía mi alma estar sin él en oración, como si con mucha gente fuera a pelear. Con este remedio, que era como una compañía o escudo en que había de recibir los golpes de los muchos pensamientos, andaba consolada) ?

La meditación propiamente dicha puede realizarse siguiendo diversos mé-

3. Camino de perfección, 25,1 .

4. Camino de perfección, 30,7.

5. Moradas primeras, 1,7.

6. Camino de perfección, 17,3.

7. Vida, 4,9 . 
todos, los cuales suponen siempre una preparación, que consiste en permanecer unos instantes en la presencia de Dios, pidiendo su ayuda; después viene el cuerpo de la meditación, un período en el que el alma se entrega a la reflexión discursiva; finalmente hay una conclusión, en la que se toman diversas resoluciones. Hay buenos libros que ofrecen sistemáticamente materia para meditar:

«Para entendimientos concertados y almas que están ejercitadas y pueden estar consigo mismas hay tantos libros escritos y tan buenos y de personas tales, que sería yerro hicieseis caso de mi dicho en cosa de oración» ${ }^{8}$.

La Santa recomienda el Libro de la oración y la meditación de Fr. Luis de Granada, y el Tratado de la oración y meditación de san Pedro de Alcántara, que hacían referencia a los misterios de la vida del Señor y de su pasión, así como a otros temas, siguiendo los días de la semana. Según ella quien tuviere costumbre de llevar este modo de oración el Señor le llevará a puerto de luz con descanso y seguridad.

Meditación simplificada. Santa Teresa tenía el temor de que la meditación discursiva detuviera a las almas en la simple actividad intelectual en cuanto tal, y no las orientara debidamente hacia Dios. Por eso no consideraba «agua viva» al discurrir (= meditación), diciendo que es preferible amar a pensar y que aunque es bueno discurrir es mejor simplificar el razonamiento tratando de poner el corazón en Dios, que es lo verdaderamente propio de la oración:

«No llamo yo esta oración, que, como digo, va discurriendo con el entendimiento, agua viva, conforme a mi entender, digo» ${ }^{9}$.

«Sólo quiero que estéis advertidos que, para aprovechar mucho en este camino y subir a las moradas que deseamos, no está la cosa en pensar mucho, sino en amar mucho" ${ }^{10}$.

«Pues, tornando a lo que decía, de pensar a Cristo a la columna, es bueno discurrir un rato y pensar las penas que alli tuvo, y por qué las tuvo, y quién es el que las tuvo, y el amor con que las pasó; mas que no se canse siempre en andar a buscar esto, sino que se esté allí con él, acallando el entendimiento" ${ }^{11}$.

Según santa Teresa los grados propios de la vida ascética son realmente dos: oración vocal y meditación, caracterizándose esta última por la actividad discursiva del entendimiento, aunque esta actividad esté muy simplificada. Por el contrario, las oraciones en las que no hay actividad discursiva del entendimiento pertenecen al patrimonio exclusivo de la mística.

8. Camino de perfección, 19,1.

9. Camino de perfeccion, 19,6:

10. Moradas cuartas, $1,7$.

11. Vida, 13,22. 


\section{EL RECOGIMIENTO INTERIOR}

Los autores espirituales al hablar acerca de los grados de oración se refieren unánimemente a la «oración de recogimiento» de santa Teresa, a la que consideran un grado de oración superior y distinto al propio de la meditación. Sin embargo, se trata solamente de un estado en el que el alma se recoge interiormente para poder rezar o meditar mejor. El conocimiento del origen de este estado y el análisis del mismo demuestran la validez de nuestra afirmación.

Hasta mediados del siglo XVI estuvo muy extendida en España la llamada vía del recogimiento o de la espiritualidad afectiva, predicada en todas partes por la Orden franciscana, constando esta forma de entender la espiritualidad de dos elementos fundamentales: el estado de recogimiento y la oración de recogimiento. El estado de recogimiento no era otra cosa sino aislarse del exterior para poder estar más atento a la oración. Francisco de Osuna, principal intérprete de esta vía, se refiere a ello diciendo que el recogimiento puede ser de dos maneras: general y especial. El primero consiste en estar continuamente sobre aviso, trayendo apaciguado el corazón y teniéndolo cerrado, sin andar continuamente en cosas mundanas; el segundo es apartarse de todas las cosas para hacer oración ${ }^{12}$. En cuanto a la oración de recogimiento radica en buscar amorosamente y con frecuencia la presencia de Dios, tratando de silenciar las potencias del alma, es decir, suprimiendo el pensamiento y la imaginación, por lo que se trata de verdadera oración contemplativa.

La vía del recogimiento en su doble vertiente fue muy conocida por santa Teresa, ya que aprendió a orar a través del Tercer Abecedario Espiritual de Francisco de Osuna ${ }^{13}$. También leyó el Arte de servir a Dios de Alonso de Madrid y la Subida al Monte Sión de Bernardino de Toledo, que estaban en la misma línea. Sin embargo, aceptando la doctrina acerca del estado de recogimiento, rechazó con todas sus fuerzas la oración contemplativa que puede realizarse en ese estado. Dice que nunca había que dejar de pensar para mantener el «sólo» amor mientras Dios no elevara el alma; hasta entonces era preciso seguir meditando, aunque fuera brevemente, y utilizar la imaginación. Suspender el pensamiento sin estar elevada el alma por Dios considera que es un desatino y muestra de poca humildad ${ }^{14}$. Afirma que la doctrina de los letrados y espirituales (franciscanos) que enseñaba a prescindir de formas y figuras «es un engaño» ${ }^{15}$. En su obra cumbre, el Castillo interior, se expresa del

12. Tercer abecedario espiritual, 15,2 .

13. Vida, 4,6.

14. Vida, 12,5.

15. Vida, 22,2 . 
mismo modo: suprimir la meditación para ejercitarse sólo en el amor «a mí no me harán confesar que es buen camino» ${ }^{16}$.

El pensamiento teresiano acerca del recogimiento adquirido queda perfectamente expresado en el Camino de perfección. Tras nombrar a san Agustín diciendo que «buscaba a Dios por todas partes y le vino a hallar dentro de sí mismo», añade:

«Este modo de rezar, aunque sea vocalmente, con mucha más brevedad se recoge el entendimiento, y es oración que trae consigo muchos bienes. Llámase recogimiento, porque recoge el alma todas las potencias y se entra dentro de sí con su Dios, y viene con más brevedad a enseñarla su divino Maestro y a darla oración de quietud, que de ninguna otra manera. Porque allí metida consigo misma, puede pensar en la Pasión y representar allí al Hijo y ofrecerle al Padre y no cansar el entendimiento andándole buscando en el monte Calvario y al Huerto y a la Columna» ${ }^{17}$.

Se deduce de este texto que se trata de un modo de rezar en el que el alma se recoge para poder pensar mejor en Dios, que es lo propio de la meditación. De hecho, aunque el alma recoja sus potencias encerrándose dentro de sí, no debe llegar a silenciarlas del todo, es decir, no debe suprimir completamente el discurso y la imaginación, que a su vez es lo propio de la contemplación:

«Entended que esto no es cosa sobrenatural, sino que está en nuestro querer, y que podemos nosotros hacerlo con el favor de Dios, que sin éste no se puede nada, ni podemos nosotros tener un buen pensamiento. Porque esto no es silencio de las potencias: es encerramiento en sí misma el alma»" ${ }^{18}$.

Para alcanzar este estado basta aislarse del exterior, procurando cerrar los ojos para estar más recogido:

«Un retirarse los sentidos de estas cosas exteriores y darles de tal manera mano que, sin entenderse, se le cierran los ojos por no las ver, y porque más se despierte la vista a los del alma. Así quien va por este camino, casi siempre que reza tiene cerrados los ojos, y es admirable costumbre para muchas cosas, porque es un hacerse fuerza a no mirar las de acá»" ${ }^{19}$.

Aislándose del exterior y cerrando los ojos se adquiere un estado de recogimiento adquirido en el que es más fácil rezar y meditar. Así se crean las disposiciones adecuadas para que aparezcan los estados místicos, en los que se realiza la oración extraordinaria.

16. Moradas sextas, 7,5 .

17. Camino de perfección, 28,4 .

18. Camino de perfección, 29,4 .

19. Camino de perfección, 28,6. 


\section{LA ORACIÓN EXTRAORDINARIA}

Para comprender bien los grados de oración ordinaria hay que saber distinguir entre el estado de recogimiento adquirido y la oración correspondiente. Lo mismo sucede en la oración extraordinaria, pues una cosa son los estados pasivos y otra la oración que se puede realizar en ellos.

La oración ordinaria, que consiste en rezar y meditar discursivamente, aunque sea en forma simplificada, se realiza en los estados de vigilia y de recogimiento adquirido. Por el contrario, la oración extraordinaria es la que tiene lugar en los estados pasivos de quietud y de unión.

\section{El estado pasivo de quietud}

La primera manifestación mística es el estado pasivo de quietud, que puede ser más o menos intenso. Cuando es poco profundo se presta a la práctica de la meditación discursiva, mientras que cuando es más profundo ayuda a estar en contemplación. Por eso en este estado pasivo se puede tener la oración de recogimiento sobrenatural y la oración de quietud.

La oración de recogimiento sobrenatural. Para un alma deseosa de llegar a la plena unión mística con Dios es muy importante conocer cuáles son las primeras manifestaciones experimentales de los fenómenos místicos. Para ello es preciso leer detenidamente las maravillosas descripciones de santa Teresa, que permiten conocerlas con todo rigor y precisión:

«La primera oración que sentí, a mi parecer, sobrenatural, que llamo yo lo que con industria ni diligencia no se puede adquirir aunque mucho se procure, aunque disponerse para ello sí y debe de hacer mucho al caso, es un recogimiento interior que se siente en el alma, que parece ella tiene allá otros sentidos, como acá los exteriores, que ella en sí parece se quiere apartar de los bullicios exteriores; y así, algunas veces los lleva tras sí, que le da gana de cerrar los ojos y no oír, ni ver, ni entender sino aquello en que el alma entonces se ocupa, que es poder tratar con Dios a solas. Aquí no se pierde ningún sentido ni potencia, que todo está entero, mas estálo para emplearse en Dios» ${ }^{20}$. «Un recogimiento que también me parece sobrenatural, porque no es estar en oscuro ni cerrar los ojos ni consiste en cosa exterior, puesto que sin quererlo se hace esto de cerrar los ojos y desear soledad y sin artificio parece que se va labrando el edificio para la oración que queda dicha» ${ }^{21}$.

«Y no penséis que es por el entendimiento adquirido, procurando pensar dentro de sí a Dios, ni por imaginación, imaginándole en sí. Bueno es esto y

20. Relación primera al P. Rodrigo Álvarez, n. 3.

21. Moradas cuartas, 3,1. 
excelente manera de meditación porque se funda sobre la verdad, que lo es: estar Dios dentro de nosotros mismos; mas no es esto, que esto cada uno lo puede hacer, con el favor del Señor se entiende todo. Mas lo que digo es en diferente manera, y que algunas veces antes que se comience a pensar en Dios ya esta gente está en el casttillo, que no sé por dónde ni cómo oyó el silbo de su pastor; que no fue por los oídos, que no se oye nada, mas siéntese notablemente un encogimiento suave a lo interior, como verá quien pasa por ello, que yo no lo sé aclarar mejor. Paréceme que he leído que como un erizo o tortuga cuando se retiran hacia sí; y debíalo de entender bien quien lo escribió. Mas éstos, ellos se entran cuando quieren; acá no está en nuestro querer, sino cuando Dios nos quiere hacer esta merced» ${ }^{22}$.

La característica esencial de este fenómeno es que aparece de manera espontánea, de tal forma que no se puede conseguir voluntariamente, por lo que es sobrenatural. Esta espontaneidad es lo que permite distinguir con toda claridad los fenómenos naturales de los sobrenaturales: los primeros se logran con el propio esfuerzo, mientras que los segundos, como dice santa Teresa, «no se pueden adquirir aunque mucho se procure». En este sentido el estado de recogimiento sobrenatural es esencialmente diferente del estado de recogimiento adquirido, que se puede lograr siempre que se quiera y lo permitan las condiciones ambientales.

Otras características de este estado son las siguientes: se siente un suave recogimiento interior, que se traduce en un verdadero bienestar. Además hay una fuerza interior que tiende a paralizar la voluntad, impulsando a cerrar los ojos, a desear la soledad y a evitar todo movimiento; es una especie de hipnosis interna que tiende a introducir a la persona en su interior, pero en la que, a diferencia de la hipnosis heterosugestiva, se tiene una perfecta claridad mental. Al mismo tiempo, la actividad sensorial sigue funcionando con normalidad.

Los teólogos afirman que la causa del éxtasis, que es un estado más profundo que el de quietud, es la contemplación infusa en un grado muy intenso, ya que cuando es débil, como sucede en el estado de quietud, no causa suspensión de las potencias ni de los sentidos corporales, por lo que es necesaria cierta intensidad de la luz contemplativa para que se produzca el fenómeno ${ }^{23}$. Sin embargo, sucede todo lo contrario: son los estados pasivos de quietud y de éxtasis los que tienden a producir la contemplación infusa. De hecho santa Teresa dice que en esta morada hay que simplificar el pensamiento, pero no suprimirlo tal como se hace en la contemplación:

«Lo que entiendo que más conviene que ha de hacer el alma que ha querido el

22. Moradas cuartas, 3,3.

23. Royo MARín, A., Teología de la perfección cristiana, Madrid 1962, p. 676. 
Señor meter a esta morada es lo dicho, y que sin ninguna fuerza ni ruido procure atajar el discurrir del entendimiento, mas no el suspenderle, ni el pensamiento... que en la del recogimiento no se ha de dejar la meditación» ${ }^{24}$.

Por tanto, la mística no comienza con la contemplación, sino con el estado pasivo de quietud, en el que al principio, según santa Teresa, no se ha de dejar la meditación.

La oración de quietud. En algunas ocasiones santa Teresa parece distinguir entre el estado de recogimiento sobrenatural y el de quietud, tal como aquí lo expresa:

«De este recogimiento viene algunas veces una quietud y paz interior muy regalada, que está el alma que no le parece le falta nada, que aun el hablar le cansa, digo el rezar y el meditar; no quería sino amar. Dura rato y aun ratos» ${ }^{25}$.

Sin embargo, analizando los caracteres psicofísicos de ambos estados se puede ver que son los mismos:

«Es ya cosa sobrenatural y que no la podemos procurar nosotros por diligencias que hagamos; porque es un ponerse el alma en paz, o ponerla el Señor en su presencia por mejor decir... Siéntese grandísimo deleite en el cuerpo y grande satisfacción en el alma. Está tan contenta de sólo verse cabe la fuente, que aun sin beber está ya harta; no le parece hay más que desear: las potencias sosegadas, que no querrían bullirse; todo parece le estorba a amar, aunque no tan perdidas, porque pueden pensar en cabe quién están, que las dos están libres. La voluntad es aquí la cautiva, y si alguna pena puede tener estando así, es de ver que ha de tornar a tener libertad. El entendimiento no querrían entender más de una cosa, ni la memoria ocuparse en más; aquí ven que ésta sola es necesaria y todas las demás la turban. El cuerpo no querrían se menease, porque les parece han de perder aquella paz y así no se osan bullir; dales pena el hablar; en decir «Padre nuestro» una vez, se les pasará una hora» ${ }^{26}$.

En ambos casos el fenómeno aparece espontáneamente, se experimenta una gran quietud en el interior, hay una fuerza que tiende a absorber a la persona hacia dentro, no disminuye la actividad sensorial, y se tiene gran claridad mental. Se trata de un mismo estado de quietud, aunque puede tener diversos grados de intensidad.

La oración de quietud, que se produce cuando el estado de quietud es relativamente profundo, se caracteriza porque el entendimiento y la memoria

24. Moradas cuartas, $3,7.8$.

25. Relación primera al P. Rodrigo Álvarez, n. 4.

26. Camino de perfección, 31,2.3. 
quedan libres de tal modo que se puede pensar, pero cuesta meditar, por lo que comienza a producirse el silencio mental propio de la contemplación.

Santa Teresa, en el libro de su Vida, se refiere a la oración llamada sueño de las potencias, que constituye la «tercera aguạ» con que se riega la huerta ${ }^{27}$, considerándola como un grado de oración superior y distinto a la oración de quietud; en las Fundaciones escribe textualmente: «Acaece muchas veces comenzar una oración de quietud a manera de sueño espiritual...» ${ }^{28}$, y en la primera relación al P. Rodrigo Álvarez dice: «De esta oración suele proceder un sueño que llaman de.las potencias... ${ }^{29}$. Pero en sus obras posteriores cambió de modo de pensar considerándola como un simple efecto de la quietud en su grado máximo de intensidad ${ }^{30}$. Por tratarse de sueño de las potencias, al menos del entendimiento, ya es verdadera contemplación:

«Ahora, pues, acaece muchas veces esta manera de unión, que quiero decir, en especial a mí, que me hace Dios esta merced de esta suerte muy muchas, que coge Dios la voluntad, y aun el entendimiento, a mi parecer; porque no discurre, sino está ocupado gozando de Dios, como quien está mirando, y ve tanto, que no sabe hacia dónde mirar; uno por otro se le pierde de vista, que no dará señas de cosa» ${ }^{31}$.

Por coger Dios la voluntad se trata del estado de quietud, y por coger el entendimiento el alma se encuentra en contemplación, pero las distracciones son innumerables:

«La memoria queda libre, y junto con la imaginación debe ser; y ella, como se ve sola, es para alabar a Dios la guerra que da y cómo procura desasosegarlo todo. A mí cansada me tiene, y aborrecida la tengo, y muchas veces suplico al Señor, si tanto me ha de estorbar, me la quite en estos tiempos. Algunas veces le digo: ¿Cuándo mi Dios ha de estar ya toda junta mi alma en vuestra alabanza, y no hecha pedazos, sin poder valerse a sí? Aquí veo el mal que nos causa el pecado, pues así nos sujetó a no hacer lo que queremos de estar siempre ocupados en Dios.

Digo que me acaece a veces, $y$ hoy ha sido la una, y así lo tengo bien en la memoria, que veo deshacerse mi alma, por verse junta donde está la mayor parte, y ser imposible, sino que le da tal guerra la memoria e imaginación que no la dejan valer; y como faltan las otras potencias, no valen, aun para hacer mal, nada. Harto hacen en desasosegar. Digo para hacer mal, porque no tienen fuerza ni paran en un ser. Como el entendimiento no la ayuda poco ni mucho a lo que le representa, no para en nada, sino de uno en otro, que no

27. Vida, 16,1 .

28. Fundaciones, 6,1 .

29. Relación primera al P. Rodrigo Álvarez, n. 5.

30. ROYO MARín, A., o.c., p. 663 .

31. Vida, 17,5 . 
parece sino de estas maripositas de las noches, importunas y desasosegadas; así anda de un cabo a otro.

En extremo me parece le viene al propio esta comparación, porque aunque no tiene fuerza para hacer ningún mal, importuna a los que la ven. Para esto no sé qué remedio haya, que hasta ahora no me le ha dado Dios a entender; que de buena gana le tomaría para mí, que me atormenta, como digo, muchas veces» ${ }^{32}$.

En la mística oriental se utilizan ciertas técnicas para combatir las distracciones involuntarias, como son la concentración mental en una frase sagrada, en una imagen religiosa o en un punto. Por el contrario, santa Teresa pasa directamente de la meditación (oración de recogimiento sobrenatural) a la pura contemplación de la presencia de Dios (oración de quietud o sueño de las potencias), de ahí las muchas perturbaciones de la memoria y de la imaginación.

A la vista de todo lo anterior podemos concluir diciendo que el primer fenómeno místico que espontáneamente aparece es el estado de quietud. Cuando es poco profundo se puede seguir meditando, produciéndose la oración de recogimiento sobrenatural, y cuando es más profundo se origina la oración de quietud, en la que el alma se entrega a la contemplación.

\section{El estado pasivo de unión simple}

Santa Teresa habla de la unión en el libro de su Vida, diciendo que es la cuarta agua para regar el huerto ${ }^{33}$, y también se refiere a ella en las quintas y sextas moradas del Castillo interior. Tiene dos variedades: la unión simple y la unión extática, tratándose de una sola cosa, aunque los efectos son muy diferentes ${ }^{34}$.

El estado psicofísico del cuerpo en la unión simple es mucho más profundo que en el de quietud, como lo prueban sus caracteres:

«Estando así el alma buscando a Dios, siente con un deleite grandísimo y suave casi desfallecer toda con una manera de desmayo que le va faltando el huelgo y todas las fuerzas corporales, de manera que si no es con mucha pena, no puede aun menear las manos. Los ojos se le cierran sin quererlos cerrar, $o$ si los tiene abiertos, no ve casi nada; ni si lee, acierta a decir letra, ni casi atina a conocerla bien; ve que hay letra, mas como el entendimiento no ayuda, no la sabe leer aunque quiera. Oye, mas no entiende lo que oye. Así que de los sentidos no se aprovecha nada si no es para no la acabar de dejar a su placer, y así antes la dañan. Hablar, es por demás, que no atina a formar palabra, ni hay fuerza, ya que atinase, para poderla pronunciar; porque toda la fuerza

32. Vida, 17,5.6.

33. Vida, 18,1 .

34. Moradas quintas, 2,7 . 
exterior se pierde y se aumenta en las del alma para mejor poder gozar de su gloria. El deleite exterior que se siente es grande y muy conocido.

Esta oración no hace daño por larga que sea; al menos a mí nunca me le hizo, ni me acuerdo hacerme el Señor ninguna vez esta merced, por mala que estuviese, que sintiese mal, antes quedaba con gran mejoría») ${ }^{35}$

Los caracteres de este estado, junto con la espontaneidad propia de todos los fenómenos pasivos, son los siguientes: el bienestar interior es mucho mayor que en el estado de quietud, y la fuerza que tiende a paralizar el cuerpo es tan grande que resulta muy difícil realizar cualquier movimiento. Además de lo anterior, que en forma menos intensa también aparecía en el estado de quietud, los sentidos comienzan a dejar de funcionar.

Desde el punto de vista intelectual en este estado no sólo el cuerpo, sino que también la mente se paraliza de tal modo que desaparecen las distracciones y el alma queda adormecida: «Así parece está el alma como adormecida, que ni bien parece está dormida, ni se siente despierta» ${ }^{36}$.

En lo que se refiere a la oración, la unión simple ha sido considerada por todos los autores espirituales como un grado de oración superior al de quietud; sin embargo, aunque el bienestar corporal es mucho mayor el alma está medio adormecida. Más tarde se alcanza el éxtasis propiamente dicho en el que el alma está completamente despierta para la práctica de la oración.

\section{El estado pasivo de unión extática}

El estado psicofísico del cuerpo en el éxtasis o arrobamiento es tan profundo que desaparece la actividad sensorial, es imposible moverse y el cuerpo se enfría. Al mismo tiempo se experimenta un gran bienestar:

«Veréis lo que hace su Majestad para concluir este desposorio, que entiendo yo debe ser cuando da arrobamientos, que la saca de sus sentidos; porque si, estando en ellos, se viese tan cerca de esta gran Majestad, no era posible por ventura quedar con vida» ${ }^{37}$.

«En estos arrobamientos parece no anima el alma ál cuerpo, y así se siente muy sentido faltar de él el calor natural; vase enfriando, aunque con grandísima suavidad y deleite. Aquí no hay ningún remedio de resistir; que en la unión, como estamos en nuestra tierra, remedio hay; aunque con pena y fuerza, resistir se puede casi siempre. Acá, las más veces, ningún remedio hay, sino que muchas, sin prevenir el pensamiento ni ayuda ninguna, viene un ímpetu tan acelerado y fuerte, que veis y sentís levantarse esta nube o esta águila caudalosa y cogeros con sus alas» ${ }^{38}$.

\footnotetext{
35. Vida, 18,10.11.

36. Moradas quintas, 1,3 .

37. Moradas cuartas, 4,2.

38. Vida, 20,3.
} 
Aunque generalmente el éxtasis es muy agradable, hay variedades del mismo en las que se padece un gran sufrimiento corporal:

«Lo más ordinario, en viéndose desocupada, es puesta en estas ansias de muerte, y teme cuando ve que comienzan, porque no se ha de morir, mas llegada a estar en ello, lo que hubiese de vivir querría en este padecer; aunque es tan excesivo que el sujeto le puede mal llevar, y así algunas veces se me quitan todos los pulsos casi, según dicen las que algunas veces se llegan a mí de las hermanas que ya más lo entienden, y las canillas muy abiertas, y las manos tan yertas que yo no las puedo algunas veces juntar, y así me queda dolor hasta otro día en los pulsos y en el cuerpo, que parece me han descoyuntado» ${ }^{39}$.

El nombre de ex-tasis ( = fuera de sí mismo) le viene a este fenómeno porque se pierde la conciencia de sí mismo, y no se puede decir si se experimenta dentro o fuera del propio cuerpo:

«Si esto pasa, estando en el cuerpo, o no, yo no lo sabré decir; al menos, ni juraría que está en el cuerpo, ni tampoco que está el cuerpo sin el alma» ${ }^{40}$.

La oración en el estado de éxtasis. Desde el punto de vista intelectual el éxtasis se caracteriza porque se paraliza la mente, por lo que desaparecen las distracciones y cuesta mucho pensar, pero, contrariamente a lo que sucede en el estado pasivo de unión simple, se tiene una gran claridad mental en lo que se refiere a la contemplación de la presencia de Dios:

«Lo que yo entiendo en este caso es que el alma nunca estuvo tan despierta para las cosas de Dios ni con tan gran luz y conocimiento de su Majestad. Parecerá imposible, porque si las potencias están tan absortas que podemos decir que están muertas y los sentidos lo mismo, ¿cómo se puede entender que entiende ese secreto?; yo no lo sé, ni quizá ninguna criatura, sino el mismo Criador" ${ }^{41}$.

Así, pues, el éxtasis es un estado psicofísico en el que se experimenta un gran bienestar interior, desaparecen las distracciones, cesa el contacto sensorial con el exterior y lleva consigo una gran claridad mental en lo que se refiere a la contemplación, por lo que supone una gran ayuda para la práctica de la oración. Dentro de este fenómeno psicofísico comienza a producirse otro fenómeno puramente intelectual de singular importancia: la contemplación perfecta de Dios, que facilita aún más la vida de oración.

La contemplación perfecta. En las sextas moradas del Castillo interior comienza santa Teresa a referirse a la contemplación perfecta, que es aquella

39. Vida, 20,12.

40. Moradas sextas, 5,8 .

41. Moradas sextas, 4,4 . 
en la que espontáneamente aparece la presencia de Dios, bien sea en la mente o en el sentimiento, y a la que más tarde se le habría de dar el nombre de contemplación infusa. Dice que las almas que llegan a conocerla quisieran mantenerla siempre, pero no pueden conseguirlo:

«Hay muchas almas, y son hartas las que lo han tratado conmigo, que, como nuestro Señor las llega a dar contemplación perfecta, querríanse siempre estar allí, y no puede ser; mas quedan con esta merced del Señor de manera que después no pueden discurrir en los misterios de la Pasión y de la vida de Cristo como antes, y no sé qué es la causa; mas es esto muy ordinario: que queda el entendimiento más inhabilitado para la meditación» ${ }^{42}$.

Indica también que como no puede alcanzarse por mucho que se intente, mientras no vuelva a aparecer «nos ayudemos en todo lo que podamos», y que hasta que muramos, por subida oración que haya, es menester esto ${ }^{43}$. Por eso, la pasividad propia de la contemplación infusa es siempre un tanto relativa, siendo necesario tomar parte activa de algún modo parà continuar estando en oración.

Nuevamente insiste en tomar parte activa en la oración diciendo que en las séptimas moradas aparece constantemente la contemplación perfecta, pero, mientras tanto, cuando no se percibe la presencia de Dios es preciso buscarla:

«Verdad es que a quien mete ya el Señor en la séptima morada, es muy pocas veces, o casi nunca, las que ha menester hacer esta diligencia, por la razón que en ella diré, si me acordare; mas es muy continuo no se apartar de andar con Cristo nuestro Señor por una manera admirable, adonde divino y humano junto es siempre su compañía. Así que, cuando no hay encendido el fuego que queda dicho en la voluntad, ni se siente la presencia de Dios, es menester que la busquemos» ${ }^{44}$.

La contemplación infusa comienza por aparecer en el estado de éxtasis de manera esporádica, pero más tarde surge también en el estado ordinario y se hace permanente.

\section{El estado de unión transformativa}

El estado psicofísico del cuerpo en la unión transformativa es el mismo que en la oración ordinaria, ya que al llegar a estas alturas los fenómenos extáticos tienden a desaparecer:

«Yo lo estoy (espantada) de ver que, en llegando aquí el alma, todos los arrobamientos se le quitan, si no es alguna vez, y ésta no con aquellos arrebata-

42. Moradas sextas, 7,7 .
43. Moradas sextas, 7,8 .
44. Moradas sextas, 7,9 . 
mientos y vuelo del espíritu, y son muy raras veces, y ésas casi siempre no en público como antes, que era muy ordinario» ${ }^{45}$.

Sin embargo, al mismo tiempo que van desapareciendo los fenómenos extáticos, se intensifica la aparición de la contemplación perfecta, de tal modo que llega a permanecer de un modo continuo. Después de decir santa Teresa que tuvo una visión intelectual de la Santísima Trinidad en la que comprendió el misterio con grandísima claridad, añade que su alma quedó espantada por percibir siempre su presencia en su interior:

«Y cada día se espanta más esta alma, porque nunca más le parece se fueron de con ella, sino que notoriamente ve, de la manera que queda dicho, que están en lo interior de su alma, en lo muy interior, en una cosa muy honda, que no sabe decir cómo es, porque no tiene letras; siente en sí esta divina compañía» ${ }^{46}$.

Más adelante precisa cómo se realiza este fenómeno diciendo: «Aparécese el Señor en este centro del alma sin visión imaginaria, sino intelectual, aunque más delicada que las dichas» ${ }^{47}$. Primeramente escribió ni intelectual ni cosa que se parezca $a$, y más tarde tachó esta cláusula escribiendo entre líneas: sino intelectual aunque más delicada que. Lo que ocurre es que tanto la visión intelectual de la Santísima Trinidad como la contemplación perfecta de la presencia de Dios son visiones intelectuales hablando en sentido genérico, pero se trata de fenómenos distintos. La primera, que es muy breve e intensa, es un fenómeno intuitivo de comprensión intelectual; mientras que la segunda, suave y persistente, sólo ayuda a mantener la atención de la mente. Precisamente por ser suave es compatible con todas las actividades propias de la vida ordinaria:

«El traer esta presencia entiéndese que no es tan enteramente, digo tan claramente, como se le manifiesta la primera vez y otras algunas que quiere Dios hacerle este regalo; porque, si esto fuese, era imposible entender en otra cosa ni aun vivir entre la gente; mas, aunque no es con esta clara luz, siempre que advierte se halla en esta compañía» ${ }^{48}$.

El último grado de oración, tal como lo propone la mística clásica, recibe el nombre de matrimonio espiritual. Se diferencia del anterior, la unión extática o desposorio espiritual, en que el alma tiene siempre la contemplación perfecta, en la que experimenta sensiblemente la presencia de Dios:

«Porque entended que hay grandísima diferencia de todas las pasadas a las

45. Moradas séptimas, 3,12 .

46. Moradas séptimas, 1,7.

47. Moradas séptimas, 2,3 .

48. Moradas séptimas, 1,9 . 
de esta morada, y tan grande del desposorio espiritual al matrimonio espiritual, como le hay entre dos desposados a los que ya no se puede apartar.

El desposorio espiritual es diferente, que muchas veces se apartan, y la unión también lo es; porque, aunque unión es juntarse dos cosas en una, en fin, se pueden apartar y quedar cada cosa por sí, como vemos ordinariamente, que pasa de presto esta merced del Señor, y después se queda el alma sin aquella compañía, digo de manera que lo entienda. En estotra merced del Señor, no; porque siempre queda el alma con su Dios en aquel centro» ${ }^{49}$.

La experiencia sensible de la presencia de Dios permanece incluso mientras se realiza cualquier actividad o se está durmiendo:

«En queriéndome divertir, nunca salía de oración; aun durmiendo me parecía estaba en ella» ${ }^{50}$.

Aunque el fenómeno de experimentar sensiblemente la presencia de Dios permanece de un modo continuo, sin embargo, no siempre se está en oración. Lo primero es algo que espontáneamente surge en la persona aunque no le preste atención, mientras que para que haya oración hace falta unirse deliberadamente a Dios por medio de la fe y el amor. Lo que ocurre es que ese fenómeno experimental ayuda mucho a hacer oración.

Como se experimenta en todo momento la presencia de Dios, aunque no se ponga atención en ello, el alma está siempre unida sensiblemente a Dios. Por eso este estado, además de matrimonio espiritual, recibe también los nombres de unión transformativa, unión consumada y deificación del alma, metáforas con las que se expresa esa realidad sensible.

La unión mística con Dios. Para conocer la verdadera naturaleza de la mística y su valor en la vida espiritual, es preciso determinar el sentido de la unión con Dios que en ella se produce. Para ello hay que distinguir tres clases de unión: teológica, experimental y sensible.

a) Unión teológica. Esta unión se produce tan pronto como el alma queda incorporada a Cristo por medio de la gracia, con lo que el hombre se hace hijo adoptivo de Dios y templo del Espíritu Santo. Permanece siempre con tal de que el hombre no mantenga deliberada y libremente una actitud existencial en contra del amor, y es independiente de la unión sensible con Dios: se puede tener la plena unión teológica con Dios sin experimentarla sensiblemente.

b) Unión experimental. Se trata de una unión de carácter puramente psicológico, que se produce siempre que el alma se encuentra en una oración auténtica y verdadera. Efectivamente, al margen de las muchas distracciones que aparecen en la oración, el que está en ella es consciente de que se encuen-

49. Moradas séptimas, 2,2.4.

50. Vida, 29,7 . 
tra con Dios, aunque no experimente sensiblemente su presencia. Esta unión experimental, pero no sensible, se tiene tanto en la oración ordinaria como en los estados místicos.

En el estado ordinario, siempre que se reza con devoción el padrenuestro, el alma está en íntima relación filial con el Padre y es consciente de ello. Lo mismo sucede cuando, dejando a un lado los pensamientos, busca amorosamente la presencia de Dios aunque no la sienta: sabe que está con él y de algún modo experimenta y capta esta unión.

En los estados místicos no siempre se experimenta la contemplación infusa: al principio sucede habitualmente en el estado de quietud, y con cierta frecuencia en el éxtasis. Pero entonces, análogamente a lo que sucede en la contemplación ordinaria, el alma sabe que está con Dios y de algún modo experimenta esta unión.

c) Unión sensible. Se trata de una forma psicológica de unión experimental en la que se es consciente de que se está con Dios, y al mismo tiempo se percibe su presencia, sea en la mente o en el sentimiento. Se produce solamente en la contemplación perfecta que surge en la unión extática y en la unión transformativa.

Con esta triple distinción podemos determinar el sentido de la unión mística con Dios. Todo el que quiera alcanzar la perfección ha de llevar una intensa vida de oración. En ésta los místicos experimentales tienen la experiencia sensible de la presencia de Dios, lo que les ayuda mucho a hacer oración, mientras que los místicos no experimentales están al margen de esa experiencia sensible. Ahora bien, la verdadera unión mística con Dios se realiza en toda oración a través de la fe y del amor, tanto si aparece la experiencia sensible como si está ausente. Por eso ha habido muchas almas que sin experimentar los fenómenos místicos han alcanzado la cumbre de la perfección.

Existe, entre otras, una diferencia fundamental entre la espiritualidad oriental y la cristiana. En la primera la unión mística con Dios es de carácter psicológico, experimental y sensible, mientras que en la segunda se realiza a través de la fe y del amor. Por eso en la espiritualidad cristiana todos los fenómenos místicos, tanto el éxtasis como la contemplación perfecta, son accidentales.

\section{LAS VISIONES}

Los fenómenos místicos que tienen relación directa con los grados de oración propuestos por la mística experimental cristiana son los estados de quietud y de éxtasis, junto con la contemplación perfecta o infusa. Al lado de ellos pueden aparecer otros fenómenos extraordinarios tales como las visiones, la 
levitación y otros de análoga naturaleza, que no juegan ningún papel esencial en los grados de oración. Entre estos fenómenos, completamente accidentales desde cualquier punto de vista que se les considere, uno de los más interesantes es el que se refiere a las visiones.

Una visión en sentido propio es la percepción de un objeto a través de los ojos corporales. Ahora bien, en sentido amplio también se consideran como visiones a la percepción de objetos a través del sentimiento, de la imaginación y de la inteligencia. Por eso, en la teología espiritual las visiones se clasifican en tres grupos: corporales, espirituales (sensitivas e imaginarias) e intelectuales. Puesto que los místicos afirman que sus visiones nunca fueron corporales, sólo interesan las espirituales y las intelectuales.

\section{Visiones espirituales}

Según san Agustín todo lo que no es cuerpo, pero es algo, se llama rectamente espíritu; y ciertamente que no es cuerpo, aunque sea semejante al cuerpo por cuanto es la imagen del cuerpo ausente ${ }^{51}$. Y como lo que no es cuerpo, pero es algo, se llama espíritu, las visiones espirituales pueden producirse tanto en la imaginación como en el sentimiento.

Visiones espirituales de carácter imaginario. La visión imaginaria es una representación visible en la que se percibe el objeto interiormente a través de la imaginación, con la misma vivacidad y claridad con que se perciben las realidades físicas externas a través del sentido de la vista. Santa Teresa tuvo muchas visiones de esta clase, como ella misma relata:

«Quiso el Señor que viese aquí algunas veces esta visión: veía un ángel cabe mí hacia el lado izquierdo en forma corporal, lo que no suelo ver sino por maravilla. Aunque muchas veces se me representan ángeles, es sin verlos, sino como la visión pasada que dije primero. Esta visión quiso el Señor la viese así. No era grande sino pequeño, hermoso mucho, el rostro tan encendido que parecía de los ángeles muy subidos que parecen todos se abrasan (deben ser lo que llaman querubines, que los nombres no me los dicen; mas bien veo en el cielo hay tanta diferencia de unos ángeles a otros, y de otros a otros, que no lo sabría decir). Veíale en las manos un dardo de oro largo, y al fin del hierro me parecía tener un poco de fuego. Éste me parecía meter por el corazón algunas veces y que me llegaba a las entrañas; al sacarle me parecía las llevaba consigo, y me dejaba toda abrasada en amor grande de Dios. Era tan grande el dolor, que me hacía dar aquellos quejidos, y tan excesiva la suavidad que pone este grandísimo dolor, que no hay desear que se quite ni se contenta el alma con menos que Dios. No es dolor corporal, sino espiritual, aunque no

51. De gen. ad litt. XII,7,16. 
deja de participar el cuerpo algo, y aun harto. Es un requiebro tan suave que pasa entre el alma y Dios, que suplico yo a su bondad lo dé a gustar a quien pensare que miento» ${ }^{52}$.

Es de destacar que el corazón de santa Teresa se conserva incorrupto en el convento de la Anunciación (Alba de Tormes), y en él se puede observar una herida horizontal en el parte superior, lo que indica que sus visiones tuvieron repercusiones somáticas.

Visiones espirituales de carácter sensitivo. La visión sensitiva es aquella en la que, sin forma ni figura, se percibe el objeto a través del sentimiento:

«Estando un día del glorioso San Pedro en oración, vi cabe mí, o sentí, por mejor decir, que con los ojos del cuerpo ni del alma no vi nada, mas parecíame estaba junto cabe mí Cristo y veía ser él el que me hablaba, a mi parecer. Yo, como estaba ignorantísima de que podía haber semejante visión, diome gran temor al principio y no hacía sino llorar, aunque en diciéndome una palabra sola de asegurarme, quedaba como solía, quieta y con regalo y sin ningún temor. Parecíame andar siempre a mi lado Jesucristo, y como no era visión imaginaria, no veía en qué forma; mas estar siempre al lado derecho, sentíalo muy claro, y que era testigo de todo lo que yo hacía, y que ninguna vez que me recogiese un poco, o no estuviese muy divertida, podía ignorar que estaba cabe mí» ${ }^{53}$.

Los teólogos incluyen este tipo de visiones entre las de carácter intelectual; sin embargo, no se producen en el entendimiento sino en el sentimiento. Pueden considerarse como una variedad de contemplación perfecta en la que se percibe la presencia de Dios a través del sentimiento. Por ser una experiencia suave y que dura mucho tiempo ayuda mucho a mantener la atención en la presencia de Dios.

\section{Las visiones intelectuales}

Hay dos clases de éxtasis: el arrobamiento y el arrebatamiento o vuelo del espíritu. El primero aparece de manera suave y tranquila, mientras que el segundo surge bruscamente:

«La diferencia que hay de arrobamiento y arrebatamiento es que el arrobamiento va poco a poco muriéndose a estas cosas exteriores y perdiendo los sentidos y viviendo a Dios. El arrebatamiento viene con una sola noticia que su Majestad da en lo muy íntimo del alma, con una velocidad que la parece que la arrebata a lo superior de ella, que a su parecer se le va del cuerpo; y

52. Vida, 29,13.

53. Vida, 27,2. 
así es menester ánimo a los principios para entregarse en los brazos del Señor» ${ }^{54}$.

Sin embargo, la diferencia es muy relativa ya que sólo se trata de variedades de un mismo estado:

«Querría saber declarar, con el favor de Dios, la diferencia que hay de unión a arrobamiento, o elevamiento, o vuelo que llaman de espíritu o arrebatamiento que todo es uno» ${ }^{55}$.

Lo que caracteriza al arrobamiento es que en él se produce la contemplación infusa, un fenómeno intelectual tranquilo, suave y permanente que facilita mucho la práctica de la contemplación. Mientras que lo propio del arrebatamiento son las noticias o visiones intelectuales, otro fenómeno intelectual muy distinto del anterior, en el que la capacidad de comprensión intuitiva de la mente se acrecienta en un grado inconmensurable. Las visiones intelectuales pueden aparecer solas o estar acompañadas de visiones imaginarias:

«Pues tornando a este apresurado arrebatar el espíritu, es de tal manera que verdaderamente parece sale del cuerpo, y, por otra parte, claro está que no queda esta persona muerta; al menos ella no puede decir si está en el cuerpo o si no, por algunos instantes. Parécela que toda junta ha estado en otra región muy diferente de en esta que vivimos, adonde se le muestra otra luz tan diferente de la de acá que, si toda su vida ella la estuviera fabricando junto con otras cosas, fuera imposible alcanzarlas. $Y$ acaece que, en un instante, le enseñan tantas cosas juntas que en muchos años que trabajara en ordenarlas con su imaginación y pensamiento no pudiera de mil partes la una. Esto no es visión intelectual sino imaginaria que se ve con los ojos del alma muy mejor que acá vemos con los del cuerpo, y, sin palabras, se le da a entender algunas cosas; digo como, si ve algunos santos, los conoce como si los hubiera tratado.

Otras veces, junto con las cosas que ve con los ojos del alma, por visión intelectual, se le representan otras, en especial multitud de ángeles con el Señor de ellos; $y$, sin ver nada con los ojos del cuerpo ni del alma, por un conocimiento admirable que yo no sabré decir, se le representa lo que digo, y otras muchas cosas que no son para decir» ${ }^{56}$.

Una de las más importantes visiones intelectuales que tuvo santa Teresa se refirió a la Santísima Trinidad:

«Aquí es de otra manera: quiere nuestro buen Dios quitarla las escamas de los ojos, y que vea, y entienda algo de la merced que le hace, aunque es por una manera extraña y metida en aquella morada por visión intelectual, por cierta manera de representación de la verdad, se le muestra la Santísima Tri-

54. Cuentas de conciencia, 54,8 .

55. Vida, 20,1.

56. Moradas sextas, 5,7.8. 
nidad, todas tres Personas, con una inflamación que primero viene a su espíritu a manera de una nube de grandísima claridad, y estas Personas distintas, y por una noticia admirable que se le da al alma, entiende con grandísima verdad ser todas tres Personas una sustancia y un poder y un saber y un solo Dios; de manera que lo que tenemos por fe, allí lo entiende el alma, podemos decir, por vista, aunque no es vista con los ojos del cuerpo ni del alma, porque no es visión imaginaria» ${ }^{57}$.

Se trata de algo tan sublime que, según san Juan de la Cruz, constituyen un contacto expreso con lo divino que penetra la sustancia misma del alma:

«Y estas altas noticias no las puede tener sino el alma que llega a la unión con Dios, porque ellas mismas son la misma unión; porque consiste el tenerlas cierto toque que se hace del alma con la Divinidad, y así el mismo Dios es el que allí es sentido y gustado. $Y$, aunque no tan manifiesta y claramente como en la gloria, pero es tan subido y alto toque de noticia y sabor que penetra la sustancia del alma, que el demonio no se puede entrometer ni hacer otro semejante, porque no le hay, ni cosa que se compare, ni infundir sabor ni deleite semejante; porque aquellas noticias saben a esencia divina y vida eterna, y el demonio no puede fingir cosa tan alta" ${ }^{58}$.

Santa Teresa no es menos explícita ya que también interpreta este fenómeno como una auténtica visión celestial: «Parece que le ha querido el Señor mostrar algo de la tierra adonde ha de ir», de tal modo que aunque es muy breve son tan grandes los bienes que produce que no puede ser obra del demonio ni de la imaginación ${ }^{59}$.

\section{LA INTERPRETACIÓN DE LA EXPERIENCIA MÍSTICA}

Hasta ahora nos hemos referido a una serie de fenómenos que tienen como característica común la espontaneidad. Ésta se manifiesta en que nadie puede producirlos cuando quiera, de tal modo que el alma puede disponerse a ellos, pero unas veces aparecen de improviso, sin ninguna preparación previa, y otras no aparecen por mucho que el alma se prepare a ello. Cuando surgen no se pueden intensificar a pesar de todos los esfuerzos del alma: nadie puede determinar con su esfuerzo un fenómeno místico concreto y determinado, sino que puede aparecer cualquiera de ellos. En ocasiones el fenómeno comienza, se intensifica y va disminuyendo poco a poco hasta desaparecer del todo, mientras que otras veces aparece y desaparece bruscamente sin que el alma haya hecho nada por provocarlo o alejarlo. Finalmente, ante el fenómeno el al-

57. Moradas séptimas, 1,6 .

58. Subida, II,26,5.

59. Moradas sextas, 5,9.10. 
ma se siente completamente pasiva, como impulsada por una realidad extraña que se apodera de ella. Otra característica común es su particularidad: son muchas las almas que han alcanzado la cumbre de la perfección espiritual sin haber experimentado estos fenómenos. De lo que ahora se trata es de interpretar su verdadero origen.

Tomando como base el éxtasis, que es el más representativo de todos los fenómenos místicos, todos los autores están de acuerdo con santo Tomás que puede tener una triple causa: natural, como sucede con los que padecen enajenación por alguna enfermedad; diabólica, como aparece claro en los energúmenos; y por la acción divina, en cuanto que alguno es elevado por el espíritu divino a las cosas sobrenaturales con abstracción de los sentidos ${ }^{60}$. La experiencia mística, que incluye el éxtasis y el resto de los fenómenos extraordinarios, es la que tiene por causa la acción divina.

Sobre la base del origen sobrenatural de los fenómenos místicos, la espiritualidad cristiana se ha dividido en dos partes: ascética y mística. La ascética es la parte de la espiritualidad cristiana que se centra en el esfuerzo ascético con el concurso de la gracia divina. La mística, como hecho psicológico, ha sido considerada unánimemente como una experiencia pasiva de lo divino, de tal modo que sólo el Espíritu Santo puede producirla en nosotros mediante el influjo y la actuación de sus dones ${ }^{61}$. En torno a estos dos polos gira toda la vida espiritual de los creyentes cristianos.

El problema que se plantea ahora es que la moderna parapsicología ha puesto de manifiesto una serie de fenómenos que, como los místicos, también se producen de manera espontánea, y sólo aparecen en algunas personas concretas y particulares: los mediums o dotados. Por tanto, es absolutamente necesario comparar dichos fenómenos para saber si la mística experimental cristiana es un edificio con sólidos cimientos o, por el contrario, es una gran construcción teológica que carece de base.

60. II-II, 175,1 .

61. Royo MARín, A., o.c., p. 239. 


\section{MÍSTICA Y PARAPSICOLOGÍA II}

\section{LA EXPERIENCIA PARANORMAL}

Fenómenos paranormales son los que se encuentran al margen de lo normal, manifestándose solamente en determinados sujetos conocidos con el nombre de paragnomos, dotados, mediums o sensitivos. Estos fenómenos tienen, entre otras, las siguientes características:

1. ${ }^{\circ}$ Se trata de experiencias espontáneas. Son susceptibles de producirse en cualquier circunstancia, aunque no se piense deliberadamente en ello, de tal modo que ordinariamente no dependen de la voluntad de la persona en la que aparecen.

$2 .^{\circ}$ No tienen explicación racional. Son experiencias extraordinarias que no están de acuerdo con los postulados de la psicología y de la física tradicional, por lo que son capaces de alterar las leyes del espacio, del tiempo y de la masa.

3. ${ }^{\circ}$ Son fenómenos que provienen de los estratos inconscientes de la personalidad, aunque se trata de unos niveles mucho más profundos que los alcanzados por la psiquiatría, de tal modo que no se puede hacer aflorar a la superficie a través de los conocidos métodos psicoanalíticos ${ }^{1}$. Para alcanzar el estado consciente deben transformarse, por ese motivo muchas veces no se reconocen como propios, dando la falsa impresión de provenir de una fuente extraña a uno mismo.

4. ${ }^{\circ}$ Se deben a facultades paranormales que son patrimonio de todo el género humano y en este sentido son facultades normales, pero su manifestación es privativa de personas especiales o de circunstancias extraordinarias. Por tanto, el fenómeno, la manifestación de la facultad, es paranormal, extraordinaria, al margen de lo normal ${ }^{2}$. Ahora bien, no tienen nada que ver con lo anormal y lo patológico, pudiéndose manifestar en personas perfectamente equilibradas y maduras.

Antes de analizar la experiencia paranormal hay que hacer referencia a los eștados alterados de conciencia, que constituyen la base de la misma.

1. RHINE, J.B., El nuevo mundo de la mente, Barcelona 1982, p. 241.

2. GonZÁlez Quevedo, O., El rostro oculto de la mente, Santander 1976, p. 31. 


\section{LOS ESTADOS ALTERADOS DE CONCIENCIA}

La conciencia psicológica puede tener diversos estados: excitación, vigilia, somnolencia, sueño ligero, sueño profundo y coma; sin embargo, también pueden producirse los llamados estados alterados de conciencia o de trance. Éste puede ser considerado como un estado hipnoide de disociación psicológica que libera, en mayor o menor grado el inconsciente del control total de la conciencia dando lugar a los fenómenos paranormales.

Los diversos estados mentales, tanto normales como alterados, pueden relacionarse con las ondas emitidas por la actividad eléctrica del cerebro. El descubrimiento lo llevó a cabo el psiquiatra alemán Hans Berger en 1924. Vio que el cerebro emitía débiles impulsos eléctricos susceptibles de medición. Pudo comprobar que en determinadas circunstancias aparecían unas ondas que, por ser las primeras en descubrirse, se denominaron ondas alfa. Más tarde se conocieron también las ondas beta, theta y delta.

Las ondas beta predominan en el estado de vigilia. El cerebro las produce cuando una persona está dedicada a las actividades propias de la vida diaria. Su amplitud es muy débil, de 15 a 20 microvoltios, y su frecuencia es de catorce a treinta ciclos por segundo; se trata, por tanto, de ondas cortas y rápidas, signo de la actividad psíquica. Las ondas alfa indican reposo sensorial y mental, produciéndose ordinariamente en el sueño ligero; su amplitud puede llegar hasta los 100 microvoltios y su frecuencia está comprendida entre los siete y los catorce ciclos por segundo; así pues, son más amplias y lentas que las anteriores. Las ondas theta aparecen en ciertas fases del sueño medio, su potencial puede ser de 200 microvoltios y su frecuencia está situada entre los cuatro y los siete ciclos por segundo. Finalmente, las ondas delta pertenecen al estado de coma y al sueño profundo, su amplitud es de 200 microvoltios a 1 milivoltio, y su frecuencia es menor de cuatro ciclos por segundo.

Las ondas alfa y theta, que acompañan siempre al descanso físico y psíquico, aparecen en el sueño de forma inmediata, pero también se pueden conseguir recurriendo a diversas técnicas de relajación psicofísica. Tienen mucho interés para la teología espiritual porque los teólogos afirman que con ciertas técnicas en la mística oriental se alcanzan estados espirituales desconocidos del común de la gente, pero que no son esos encuentros experimentales con Dios en que él nos transforma a su semejanza ${ }^{3}$. Sólo conociendo de cerca estas técnicas y sus efectos se podrá ver la validez de esta afirmación.

3. Bernardo, P.M., Santa Teresa: la oración y la contemplación, Madrid 1977, pp. 86-87. 


\section{Técnicas de relajación psicofísica}

Las siguientes técnicas de inspiración oriental producen inmediatamente el trance ligero a toda clase de personas, y con ellas los dotados también pueden alcanzar el trance profundo, logrando resultados realmente espectaculares. Se centran en permanecer inmóvil y concentrado hasta que el cuerpo y la mente queden completamente relajados. Para realizarlas basta sentarse cómodamente o tumbarse sobre la cama, repitiéndolas mentalmente a la vez que se concentra la atención en ellas. También pueden decirse en voz alta para que las escuchen los demás.

\section{Concentración mental en la respiración}

Cierra los ojos.

Haz una inspiración profunda y al expirar afloja todos los músculos de tu cuerpo, sintiéndote mejor, mejor y mejor.

Haz otra inspiración profunda y al expirar vuelve a aflojar todos los músculos de tu cuerpo, sintiéndote mejor, mejor y mejor.

Haz otra inspiración profunda y al expirar vuelve a aflojar todos los músculos de tu cuerpo, sintiéndose mejor, mejor y mejor.

\section{Concentración mental en un pozo profundo}

Concéntrate en un pozo muy profundo. Imagina que vas a descender por él. Voy a contar de diez a uno. A medida que vaya contando de diez a uno sentirás que desciendes profundamente. Experimenta la agradable sensación de descender:

$10-9-8$ más y más profundo

7-6-5 más y más profundo

4 - 3 más y más profundo todavía

$2-1$

Concentración mental en la sensación de pesadez

Te encuentras ahora en un estado muy relajado y profundo. Para que puedas entrar en un estado más relajado y profundo todavía, vas a sentir cómo pesa tu propio cuerpo:

Concentra tu atención en la pierna derecha... tu pierna derecha se vuelve muy pesada... más pesada... cada vez más pesada... se ha convertido en plomo pesado... es tan pesada que no puedes levantarla... más y más pesada todavía.

Concentra tu atención en la pierna izquierda...

Concentra tu atención en el brazo derecho... 
Concentra tu atención en el brazo izquierdo...

Concentra tu atención en la espalda...

\section{Concentración mental en la sensación de calor}

Te encuentras ahora más relajado y a gusto que antes. Para que puedas entrar en un estado más relajado y profundo, vas a concentrarte en la sensación de calor de tu propio cuerpo:

Concentra tu atención en el vientre... siente los músculos del vientre... relaja los músculos del vientre... siente calor en el vientre...

Concentra tu atención en la cintura...

Concentra tu atención en la espalda, hombros, mandíbulas, ojos...

\section{Salida}

Voy a contar del uno al diez. Al llegar a diez te encontrarás completamente descansado, tranquilo y mucho mejor que antes:

1 - 2 - 3 más y más despejado

4- 5 - 6 más y más despejado

7 - 8 más despejado todavía

Al principio tarda en producirse el efecto de relajación, siendo necesario utilizar varias de estas técnicas, pero con el tiempo basta cerrar los ojos y contar de diez a uno para conseguir inmediatamente lo que se pretende. Una vez que se ha alcanzado el estado de relajación se puede aprovechar para la práctica de la oración contemplativa.

\section{El trance autoprovocado}

Los fenómenos paranormales pueden clasificarse en razón de su forma de aparición en espontáneos y de laboratorio. En principio todos los fenómenos son espontáneos, pero muchos de ellos pueden producirse en el laboratorio bajo un cierto control y dominio de la voluntad. Bajo este punto de vista trataremos ahora del trance voluntariamente provocado por uno mismo, utilizando las anteriores técnicas de relajación. Lo analizaremos en función del grado de profundidad alcanzado, los sentimientos internos que se experimentan, la claridad mental que se consigue y el tiempo que dura.

Grado de profundidad. Voluntariamente los dotados pueden alcanzar los estados correspondientes a las ondas alfa y theta, por el contrario, el correspondiente a las ondas delta no es fácil conseguirlo de este modo.

El estado alfa está al alcance de todo el mundo, por lo menos en un nivel no muy profundo, pero sus manifestaciones son poco intensas. En él se nota 
entumecimiento en los miembros y una cierta pesadez en el cuerpo, como lo expresan estos testimonios:

«He logrado un cierto entumecimiento, pero no he conseguido bajar a un grado muy profundo por mucho que lo he intentado».

«Siento entumecimiento por todo el cuerpo».

Aparentemente hay un trance ligero, otro intermedio y otro profundo; sin embargo, las ondas mentales indican que sólo aparecen los estados alfa y theta. Las siguientes descripciones corresponden a las primeras manifestaciones del estado theta, tratándose de unos niveles en los que hay una gran paralización en los miembros y se comienza a no sentir el cuerpo:

«Siento una gran paralización en los brazos y en las piernas, pues quiero moverlas y no puedo. Con grandes esfuerzos algunas veces lo consigo hacer, aunque no siempre».

«Siento paralización y en algunas ocasiones no siento los pies. Me produce una enorme pesadez».

En un nivel aún más profundo deja de sentirse el cuerpo, pero permanece todavía el sentido del oído:

«Yo estaba en un nivel en el que no sentía el cuerpo, pero oía. Algo me hacía daño, pero no lo sentía. En cambio, cuando salí empezó a dolerme».

«Cuando hago esto sí oigo, pero lo único que siento es la cabeza. Es como si la tuviera suspendida en el aire».

Finalmente, en los niveles más profundos del estado theta, se llega a perder totalmente el sentido del oído, cesando totalmente la actividad sensorial:

«Iba oyendo de una manera cada vez más débil. Su voz se oía como un eco que se pierde en el espacio».

"Yo no siento el cuerpo y algunas veces oigo algo, pero otras me quedo completamente sordo y no percibo nada de lo que ocurre en el exterior».

Después de numerosas experiencias realizadas con grupos de jóvenes, en los que se producen con relativa facilidad estos fenómenos, se ha podido comprobar que el trance autoprovocado se alcanza en una proporción parecida a la de la hipnosis heterosugestiva. El estado alfa lo consiguen todos los participantes sin ninguna dificultad. A los primeros niveles del estado theta llegan aproximadamente el cuarenta por ciento, y los niveles profundos del estado theta lo alcanzan solamente un diez o un veinte por ciento de los participantes. Existe una gran relación entre los fenómenos paranormales y el trance profundo, de tal modo que los que frecuentemente experimentan fenómenos de percepción extrasensorial puede decirse de antemano que fácilmente lograrán llegar al estado theta.

Sentimientos internos. La mayoría de las personas sólo experimentan una 
agradable sensación de bienestar, análoga a la que se produce después de un sueño tranquilo y reparador. Por el contrario, el grupo de los dotados puede tener sentimientos internos realmente extraordinarios. La descripción de sus experiencias habla de paz, alegría, tranquilidad, armonía y felicidad en grado muy intenso:

«Siento más bien un estado de paz y descanso mental tan grande que no se puede expresar».

«Sentí un gran placer, como si estuviera en otra dimensión».

"Siento alegría y una paz enorme. Me encuentro muy a gusto».

«Mucha tranquilidad, paz, armonía y miedo. No puedo entenderlo».

«Simplemente maravilloso. Quietud, tranquilidad, esperanza, bienestar, gratuidad, mejoramiento, infinito».

«Me siento relajada y en un estado maravilloso que me es imposible describir».

«Es algo fantástico e inimaginable».

«Mientras descendía me sentía muy bien ya que me encontraba completamente descansado y a gusto. Es una de las sensaciones más maravillosas que he tenido».

«Siento un grado de felicidad enorme dentro de mi cuerpo y por eso no quiero salir, y aun después de salir me dura un buen rato una gran felicidad interior. Es fabuloso».

Estas experiencias también producen miedo. Es como introducirse en un mundo misterioso en el que se tiene la sensación de que no se va a poder salir:

«Todavía no logro vencer el miedo y siempre pienso que no podré salir y por eso no entro. Cuando logre vencer el miedo seguro que conseguiré un nivel muy profundo, ya que hay momentos en que siento que lo alcanzo».

«Siento miedo. No sé con exactitud el porqué, quizá sea porque creo que me voy a quedar abajo y no podré salir, y por eso me asusto un poco».

Ordinariamente los que llegan a niveles profundos experimentan una fuerte sensación de descenso, como si cayeran por un pozo profundo, pero también se puede tener la impresión de entrar en un túnel o de estar flotando:

«He ido cayendo por un pozo de forma vertical. Es muy difícil de explicar pues a medida que voy cayendo se cierran las paredes de los lados, y siento miedo al pensar que no podré salir de alli. Voy acercándome cada vez más a una luz maravillosa que me da un grado de satisfacción y felicidad total. Siempre que lo hago me pasa lo mismo, unas veces más y otras menos, pero siempre lo mismo».

«Veo un túnel e incluso me siento a mí misma corriendo a través de él, pero es interminable, oscuro, con algunas luces de vez en cuando. Al fondo suele aparecer una imagen blanca a la que identifico con Dios, pero me es imposible alcanzarla pues está siempre al fondo y el túnel es interminable». 
«A veces no siento el cuerpo y me parece que estoy flotando en el aire, mientras mi cuerpo permanece en tierra».

Con frecuencia en estos estados se tienen sensaciones espirituales realmente intensas y gratificantes:

«No siento el cuerpo, noto en cambio como si una energía divina y sobrenatural me devorase con gran intensidad. Me encuentro muy a gusto porque me ayuda a entrar en el mundo de nuestro Padre».

«En este estado me encuentro completamente unido a todos, y siento el amor que hay en todos. Puedo sentir el amor de una forma increíble».

También se producen sensaciones desagradables como las de calor, mareo y dolor de cabeza:

«Paso un mal rato ya que el calor es como si me quemara. Cada vez que entro es como meterme en medio del fuego, y cada vez es más fuerte el calor».

«No me gusta entrar en trance porque luego al salir me duele mucho la cabeza».

«Siento vértigo, como si hubiera estado caminando por un sendero muy estrecho y debajo hubiera un gran abismo en el que no se ve el fondo».

La variedad de estos sentimientos subjetivos es inmensa, y depende totalmente de las características psicofísicas y paranormales de la persona que los experimenta.

Estado mental. En el estado alfa se tiene más claridad mental que en el estado de vigilia, ya que la mente se encuentra relajada, tranquila y retirada del exterior, por lo que es muy adecuado para reflexionar. También es un estado muy adecuado para concentrar la mente en la oración contemplativa, aunque aparecen innumerables distracciones. Por el contrario, en el estado theta autoprovocado se paraliza la mente, con lo que desaparecen las distracciones:

«Al principio me distraigo, pero cuando estoy en lo profundo la mente se me pone en blanco y no pienso absolutamente nada».

«Mis distracciones son pocas, mi mente se paraliza y no pienso en nada. No siento a los que me rodean y hacen ruido. No sé explicarlo».

Comparando el estado alfa con el theta cuando se ha producido voluntariamente, se puede constatar que en este último los sentimientos de paz y bienestar son mucho más intensos, y además desaparecen las distracciones; sin embargo, se tiene menos claridad mental:

«Este estado lo consigo según la disposición en la que me encuentro. Si estoy cansada no puedo llegar, y me siento mejor en el estado alfa; pero si estoy descansada y sin problemas me encuentro mejor en el theta. En cuanto a la oración es mejor el alfa, ya que en el theta me paralizo mentalmente y no tengo dominio; mis ideas y mis intenciones se mezclan y no puedo lograr mis objetivos». 
«Es un estado donde te encuentras a gusto, relajado y tranquilo, pero las ideas están confusas y algunas veces no se entienden. Es como si la mente estuviera adormecida».

Todas estas experiencias llevan a la conclusión de que, cuando sea posible, es conveniente relajarse físicamente para alcanzar el estado alfa ya que en él se hace mejor la oración.

Duración. Aunque en estos estados se tiene un gran bienestar interior tienen el inconveniente de que duran poco tiempo, de tal modo que al cabo de algunos minutos se sale forzosamente de ellos sin que sea posible hacer nada para continuar del mismo modo. Pero hay algunos dotados que alcanzan estados especiales cuya duración es indefinida:

«Lo he hecho muchas veces, tantas que no podría decir el número exacto; podrían ser dos o tres veces a la semana desde hace año y medio. Al principio me duraba poco, alrededor de veinte a treinta minutos, pero después de varios meses he llegado a estar hora y media, y he salido porque he querido, no porque no pudiera estar más».

«Me resulta dificilísimo concentrarme el día en que ceno mucho, pero cuando me acuesto con el estómago vacío consigo estar tres horas concentrada, en un profundo estado de relajación».

El fenómeno aquí descrito es un éxtasis en el que se tiene mucha claridad mental, se está muy a gusto y dura mucho tiempo, pero son muy pocos los qué pueden conseguirlo.

\section{El trance espontáneo}

Los grandes dotados que habitualmente se entregan a la práctica de la relajación y de la concentración mental, con frecuencia entran espontáneamente en trance. Aquí tenemos una descripción de lo que posiblemente es el estado alfa paranormal:

«Una noche estaba concentrada en Dios cuando de pronto me sucedió una cosa muy extraña. Era algo así como si de repente hubiera bajado algunos escalones y me encontrara en medio de una oscuridad muy intensa; una especie de oscuridad en medio de la oscuridad, pues me encontraba con los ojos cerrados. Sentí miedo ya que me dio la impresión de haberme quedado ciega, por lo que abrí los ojos, con lo que terminó esta maravillosa experiencia. No la olvidaré nunca pues me encontraba llena de paz y de bienestar. No he vuelto a sentir una cosa igual».

También puede producirse un trance intermedio, equivalente a los primeros niveles del estado theta, en los que hay una fuerte paralización corporal y mental:

«Muchas veces en clase, quizá porque tengo que estar escuchando al profesor, me encuentro totalmente alejada de lo que se habla o de lo que se dice. 
Es decir, oigo lo que dicen, pero no entiendo lo que hablan. No puedo explicarlo, porque no se trata de que no entienda lo que están diciendo, sino que mi mente se cierra y no puede entrar nada en ella. Me encuentro sin ganas de moverme y sin poder hablar, con los ojos abiertos y abobada. Esto me sucede espontáneamente, sin yo quererlo, y no puedo provocarlo».

Una variedad de este fenómeno permite realizar mecánicamente cualquier actividad al mismo tiempo que la mente se encuentra en un mundo aparte:

«A veces, cuando voy por la calle, sin querer siquiera, noto en mí una especie de arrobamiento que me hace caminar como transportada en una nube, sin oír, casi sin ver, tan sólo guiada por una especie de instinto extraño a mí misma que me conduce. Cuando voy llegando al lugar de destino hay algo que me hace salir de este estado sin yo desearlo».

En el budismo zen este fenómeno recibe el nombre de zanmai, palabra que designa un profundo recogimiento que puede tener diversos grados, pudiendo ser tan profundo que uno quede totalmente absorto, con la atención desconectada de toda otra realidad. Puede producirse también fuera de la meditación, incluso cuando uno está ocupado en otras cosas. Pero no equivale exactamente al éxtasis, en el que queda completamente en suspenso la actividad sensorial ${ }^{4}$.

El éxtasis propiamente dicho, aquel en el que desaparece completamente la actividad sensorial, también puede surgir de manera espontánea:

«Generalmente por las noches acostumbro a concentrarme. Por experiencia personal prefiero el trance ligero, que es cuando mejor capto la presencia de Dios, ya que a medida que voy bajando la mente se me queda en blanco y no logro captar nada. En estados profundos no hay claridad de ideas y la visualización de imágenes es muy difícil, aunque desaparecen las distracciones.

A veces me ocurre que estoy divagando y no me centro en nigún punto fijo, pero de repente, en un instante, comienzo a ascender y todo gira a mi alrededor. Más tarde mi cuerpo se estabiliza y tengo una felicidad inenarrable. No veo nada, pero tengo la presencia de Dios, lo noto claramente a mi lado, pero no veo nada. No me distraigo nunca en este estado y el tiempo de permanencia en él es el que yo quiera. Al salir me encuentro muy a gusto y descansada. Tardé en tener esta experiencia unas tres semanas, al intentar concentrarme por las noches un rato. Ahora hay veces en que estoy varios días sin lograr nada, pero hay otras en que el resultado es matemático. El esfuerzo que hay que realizar es muy pequeño y la recompensa es inmensa».

Ahora estamos en condiciones de determinar el verdadero origen de los fenómenos extáticos que se producen en la mística, pues ha quedado perfectamente demostrado que los estados pasivos de quietud y de unión no son sino

4. ENOMIYA-LASSALle ${ }_{2}$ H., El Zen, Bilbao 1977, p. 63. 
estados alterados de conciencia aparecidos espontáneamente. Los fenómenos extáticos constituyen una experiencia puramente natural y psicológica, pero la fe y el amor pueden hacer que en ella se tenga verdadera oración sobrenatural.

\section{LA CONTEMPLACIÓN PARANORMAL}

En el éxtasis comienza a producirse la contemplación paranormal, que consiste en la percepción experimental y sensible de la presencia de Dios. Tres experiencias aparecen espontáneamente en este estado para dar lugar a la contemplación paranormal: el vacío mental, el sentimiento sensible y la percepción intuitiva de la presencia de Dios.

Utilizando las técnicas de relajación psicofísica que hemos descrito, en muy poco tiempo una joven estudiante, Margarita P., experimentó la contemplación paranormal bajo las formas de vacío mental y sentimiento sensible de la presencia de Dios:

«Acostumbro a relajarme durante la noche; en este estado no tengo ningún contacto con el exterior, y es como si estuviese durmiendo, aunque me encuentro completamente despierta y consciente de lo que ocurre dentro de mí. Al principio me doy cuenta de lo que ocurre fuera, pero a medida que va pasando el tiempo parece como si estuviera bajando por un pozo muy profundo, y cuando llego el final me da la impresión de estar en otro sitio y no donde me encuentro realmente. No sé cómo explicarlo.

Una vez que ya estoy completamente relajada y en «el fondo del pozo», me concentro en la palabra «Dios», y es entonces cuando empiezo a notar su presencia a mi lado, aunque no veo nada. Es una sensación parecida a la que se siente cuando se va por una calle solitaria y oscura y se siente la sensación de que hay alguien detrás, aunque en realidad no hay nadie. Por eso muchas veces pienso que esto que me pasa no es tener verdaderamente la presencia de Dios, sino que es mi propia mente la que crea esta sensación de que él está conmigo. Sea lo que fuere, lo cierto es que se trata de una sensación muy intensa, siempre se me presenta de la misma forma y no me distraigo cuando la tengo.

Otras veces me concentro, y aunque digo repetidamente la palabra «Dios» no logro captar absolutamente nada y mi mente está completamente en blanco. Estas dos sensaciones diferentes son las que me ocurren. Hay veces en que le capto y otras en las que no, sucediéndose ambas por temporadas.

El bienestar que se siente en la relajación profunda es muy grande, es como estar flotando teniendo el cuerpo completamente descansado. Empecé a hacerlo el año pasado y muy pronto conseguí experimentar lo que he contado. Todo esto me ha ayudado mucho a desarrollar mi mente y a acercarme más a Dios».

La contemplación paranormal sólo se produce en los grandes dotados capaces de alcanzar voluntariamente el estado theta. Al principio únicamente 
aparece en el trance profundo, pero más tarde surge también en el estado de vigilia. Asimismo, comienza surgiendo de manera esporádica, pero si se practica mucho la concentración mental puede llegar a ser permanente:

«Si tienes el conocimiento del Ser o Brahman todo el tiempo sin interrupción, estarás establecido todo el tiempo en el Ser. Éste es un estado que tiene que ser experimentado interiormente, que no se puede expresar con palabras. Es el estado final de la paz, la meta de la vida. Esa experiencia te dará la liberación de todas las formas de esclavitud» ${ }^{5}$.

Los que alcanzan esta situación en la que se tiene continuamente la presencia de Dios pueden mantenerla mientras están durmiendo: «Aun en sueños estarás en comunión con el Señor» ${ }^{6}$. Efectivamente, se llega a soñar con Dios.

Junto al vacío mental y al sentimiento sensible de la presencia de Dios, también puede aparecer la contemplación intuitiva. Se trata de una experiencia en la que se le capta a través de la mente y no del sentimiento, como se expresa en este relato:

«Durante algún tiempo siempre que entraba en trance captaba la presencia de Dios, tanto en el sentimiento como en la mente, sobre todo en esta última. No era nada extraordinario, sólo algo así como una pequeña luz en medio de la oscuridad, como si en ella hubiera una linterna que estuviera alumbrando. En ocasiones parecía que la linterna tenía las pilas bien cargadas, mientras que otras veces apenas se podía percibir su luz. Ciertamente no tenía nada que ver con la imaginación, pues cuando más tarde he querido volver a tenerla no me ha sido posible; se podría decir que se trataba de una luz psíquica que me ayudaba a mantener la atención. Me hacía sentirme a gusto, pues con ella me distraía menos y me acercaba más a Dios. Sin embargo, después se marchó del mismo modo que vino, sin que pudiera hacer nada por retenerla, $\mathrm{y}$ entonces tuve que volver a concentrarme en una palabra para no distraerme».

Una persona excepcionalmente dotada para los fenómenos paranormales, María E., entregada desde su infancia a una intensísima vida de oración, favorecida por la espontánea aparición del fenómeno de la contemplación paranormal, tuvo la siguiente experiencia:

«Hace algún tiempo que tengo el sentimiento de que mi padre está dentro de mí; me da la impresión de que si me abren por dentro encontrarían otra persona viviendo en mi interior. Hay veces en que lo capto en mi mente, igual que a Jesús, y hay veces en que lo siento en mi interior, y también hay ocasiones en que le he visto, igual que si estuviese viviendo. Se me aparece de diversas maneras, pero siempre tal como era cuando estaba conmigo. Lo veo contento, con la misma expresión que tenía; me habla y yo le contesto; y me siento muy contenta, pero cuando me doy cuenta de que ha muerto me pongo

5. Sivananda, S., Concentración y meditación, Madrid 1977, p. 304.

6. SivanANDA, S., o.c., p. 291. 
muy triste. Sé muy bien que Jesús es quien vive en mí, y si mi padre está en el cielo, también se encuentra dentro de mí, ya ría, coma, llore o camine. En todo momento siento y capto su presencia.

Aunque captarle así es maravilloso, la verdad es que, sin embargo, me quita mucho la presencia de Jesús. Tengo constantemente ambas presencias juntas, y ahora tengo que esforzarme mucho para concentrarme en Jesús, tratando de olvidar a mi padre para que no me distraiga en la oración».

En este relato, a pesar de su brevedad, aparecen cuatro formas experimentables y sensibles de percibir la presencia de la persona ausente: en la mente, en la imaginación (visión alucinatoria de su padre), en el oído y en el sentimiento; al mismo tiempo aparece continuamente la presencia de Dios. Al cabo de algún tiempo desapareció la cuádruple experiencia sensible de la presencia de su padre, producida por la fuerte impresión producida por su fallecimiento, permaneciendo sólo la de Dios. Ciertamente, la contemplación de Dios y la de su padre constituyen un fenómeno psicológico de la misma naturaleza, y no hace falta recurrir a intervenciones extramundanas para explicarlo.

En definitiva, la contemplación perfecta, en cuanto fenómeno psicológico, es una realidad puramente natural que se explica a través de las manifestaciones del psiquismo inconsciente. Sólo la fe y el amor la convierten en oración sobrenatural.

\section{LAS ALUCINACIONES}

Una alucinación es la percepción de una visión o de una sensación sin un objeto que la produzca. Puede darse en cualquiera de los sentidos y a veces puede ser multisensorial, afectando a varios sentidos a la vez, de tal forma que se puede ver y tocar a una falsa aparición al mismo tiempo que se habla con ella.

Las alucinaciones pueden ser paranormales y no paranormales: las primeras son desencadenadas por la percepción extrasensorial, mientras que las segundas son producidas directamente por el inconsciente. En ambos casos se trata de fenómenos PK de influencia del psiquismo sobre la materia, de tal modo que el inconsciente produce las impresiones cerebrales que dan lugar al fenómeno, dándole un realismo tan vivo que puede llegar a ser verdaderamente sorprendente y extraordinario.

\section{Visiones alucinatorias}

En el gran conjunto de fenómenos alucinatorios ocupa un lugar muy destacado el que se refiere a las visiones religiosas. Pueden llegar a verse con la misma claridad con la que se perciben los cuerpos físicos presentes. Por otra 
parte, como siempre se producen en estado de trance, suelen estar acompañadas de un indescriptible gozo, paz y bienestar, lo que produce una falsa sensación de autenticidad. Son muy frecuentes entre los jóvenes adolescentes que, siendo dotados, practican habitualmente la relajación y la concentración. Se pueden exponer muchos relatos como éste:

«Al estar concentrada logro sentir en mi interior una paz difícil de explicar. Sé que estoy en el mundo, pero me siento como si estuviera en otra parte. Hay veces, aunque no siempre, que veo a Jesucristo muy claro, como si estuviera ante él, con su túnica blanca, muy blanca».

Aunque generalmente en el trance se tiene sensación de bienestar, también hay algunos estados alterados de conciencia en los que se siente sufrimiento, por eso la visión de ciertas imágenes puede ir acompañada de este sentimiento:

«Cuando me concentro en la presencia de Dios siempre me viene a la mente su misma imagen, la de Jesús crucificado. Le veo vivo, real, de tal modo que de alguna manera me transmite su dolor y sufrimiento, por lo que me pongo muy triste. No creo que tenga nada que ver con mi personalidad, pues no soy pesimista, pero me sucede así».

Un conocido fenómeno místico es el «don de lágrimas». No faltan ocasiones en que acompaña a la visión de imágenes religiosas:

«Una vez me ocurrió algo sorprendente. Me vino a la mente la imagen del Señor con la Virgen María, y al ver esto me asusté y salí enseguida de la concentración. Otras veces me vinieron las lágrimas y al terminar estaba la mesa húmeda. A mí este fenómeno me parece muy raro y no sé cómo explicarlo».

Al tratarse de fenómenos inconscientes la experiencia puede tener innumerables variedades. Puede ocurrir que se trate de una visión normal, pero que en ella haya algo extraordinario, como dice este relato:

«Muchas veces estando concentrada se me ha aparecido Jesús. Su aspecto es normal, pero tiene unos ojos tan maravillosos y profundos que al mirarme me conmueven profundamente y me traspasan el alma. Siempre se me presenta de la misma forma, con esa mirada tan intensa que no se puede describir».

Hay alucinaciones multisensoriales en las que se puede tocar a la imagen que se presenta y hablar con ella:

«Una vez se me apareció la Virgen de Lourdes. Nunca la había visto, pero supe que se trataba de ella porque después pude ver su imagen en una revista. Me cogió de la mano y estaba muy caliente, después soltó una lágrima y se desvaneció. Cuando lo conté me dijeron que a un niño también le había pasado lo mismo».

«Cuando estoy concentrada me viene a la mente la figura de Moisés con los diez mandamientos en la mano, y creo que me viene esa imagen porque la 
tengo en la Biblia, y la verdad es que me impresiona bastante. Algunas veces me habla y me contesta cuando le pido consejos. Se trata de una voz familiar ya que la de mi abuelo, que ya murió, era igual».

No faltan las ocasiones en que una figura religiosa se le aparece a una persona para comunicarle algo que está sucediendo o que sucederá después. En este caso se trata de una alucinación paranormal, por ser los factores ESP los desencadenantes de la misma:

«Hace algún tiempo tuve un gran problema familiar. Le pedí intensamente al Señor, con toda devoción, que me lo resolviera, y entonces se me apareció Jesús crucificado con toda perfección y detalle, como si no hubiera estado contemplando en el Calvario. En aquel mismo momento el problema quedó completamente resuelto».

Junto a las percepciones alucinatorias también existen las semialucinatorias, en las que un objeto físico y real parece moverse:

«A veces, cuando estoy un poco distraída, en las nubes, miro un cuadro de la Virgen y tengo la sensación de que se mueve; en unas ocasiones sonríe y en otras llora. También me pasa con un cuadro de Jesús. Si he hecho algo que sé que está mal y miro al cuadro parece como și el Señor estuviera enfadado. Por eso siento algunas veces miedo al mirar un cuadro de la Virgen o del Señor».

Todos los fenómenos que hemos descrito son reales y verdaderos, de tal modo que los videntes perciben a Jesús y a la Virgen con la misma claridad con la que fueron vistos por los hombres de su tiempo. El error puede estar al interpretar el origen de la visión, creyendo que proviene del otro mundo cuando todo esto tiene perfecta explicación natural.

\section{Sensaciones alucinatorias}

Tan frecuentes como las alucinaciones visuales son las sensitivas. Las experiencias que se pueden mostrar en este campo son innumerables, siendo posible sentir al lado de uno mismo la presencia de cualquier ser concreto, dependiendo de los contenidos de la mente inconsciente:

«Cuando me relajo y me concentro me encuentro muy bien. He llegado a sentir e incluso he podido hablar con una perrita que tenía antes y a la que tenía mucho cariño. Hablo con ella como si se tratara de mi mejor amiga. Nos comunicamos perfectamente y le cuento mis problemas. No sé si yo hubiera podido solucionarlos, pero ella me ha dado la respuesta. También le he pedido consejos y me los ha dado. Luego, para despejarme y dejar de sentir su presencia he tenido que darme un baño, porque durante algún tiempo la sigo notando a mi lado. Como la perrita hace tiempo que murió hay algunas veces en que me da miedo su presencia».

Alucinaciones de esta clase son las utilizadas por los adeptos al control 
mental con objeto de ponerse en contacto con la inteligencia de su mente inconsciente.

Lo mismo que ocurre con las alucinaciones visuales, estas experiencias frecuentemente tienen sentido religioso. Algunos sienten a Dios a su lado, otros en su interior, y también hay quienes tienen la impresión de que les está mirando:

«Hace poco, cuando me concentraba, sentí la presencia de Dios, y lo sentía tan cerca que en realidad parecía que estaba a mi lado, y me decía que todo me iba a salir bien si seguía concentrándome; parece muy extraño, pero así fue. Más tarde, después de haberme concentrado me sentía tan bien que no podía dormir. Era como si le necesitara mucho más que ocho horas de sueño».

"Yo he llegado a una concentración tan profunda que he sentido a Dios dentro de mí, y esas veces, que han sido pocas, he llegado incluso a no oír nada, estando rodeada de gente».

«Cuando me concentro me encuentro muy bien y a gusto, y con mucha frecuencia siento como si Dios me estuviera mirando, estando muy cerca de mí. Entonces hago mucho mejor la oración porque al sentir su presencia me distraigo mucho menos».

Del mismo modo que se puede sentir la presencia de Dios puede aparecer la sensación de que está cerca el demonio, aunque esto es mucho menos frecuente. Una aterradora experiencia de este tipo es la siguiente:

«Sentía desesperación angustiosa, horrible, indescriptible. No tengo palabras para explicar el terror que me atenazaba, y me daba cuenta de que esta sensación me la producía la presencia del demonio, presencia que por supuesto no vi. En este estado de ánimo, que por nada del mundo quisiera volver a pasar, invocaba a Dios con todo el corazón, y nunca mejor dicha esta frase. Después sentí que me tranquilizaba porque el demonio se marchó. El cabello de la cabeza lo sentía como si fuese alambre, y el vello del brazo lo tenía completamente rígido».

Todas estas experiencias son fruto de la espontánea manifestación del inconsciente. Es natural que la conciencia psicológica no reconozca como propio lo que proviene del inconsciente, por lo que tiende a atribuirlo a otra mente, a otra voluntad, a otra persona. Estas segundas personalidades artificiales con las que el inconsciente se encubre han recibido muchos nombres en psiquiatría: doble o múltiple personalidad, personalidad segunda, desdoblamiento psíquico, personalidades alternantes, etc. En parapsicología, esto es, cuando van acompañadas de fenómenos parapsicológicos que así se dramatizan o personifican, son llamadas prosopopeyas. Éstas pueden ser de inspiración divina, demonológica o espiritista. También pueden atribuirse, no a una persona o a un ser, sino a una pretendida vida anterior del propio dotado, todo según la interpretación subjetiva que le quiera dar el que experimenta estos 
fenómenos ${ }^{7}$. Así pues, todo lo que hemos descrito hasta ahora tiene explicación natural y procede de las profundidades del propio psiquismo inconsciente.

\section{Teología de las visiones religiosas}

Para conocer la verdadera naturaleza de las visiones místicas hay que tomar las apariciones apostólicas como punto de referencia, sólo entonces se puede determinar su verdadero sentido. En las apariciones apostólicas los evangelistas muestran que no se trata de una simple invención subjetiva de los interesados, debida a una fe exacerbada o a una imaginación desbocada. La iniciativa pertenece al Resucitado, lo que se expresa con el verbo ophthe «se hizo ver». De esta forma la fe es una consecuencia del encuentro, no su causa ${ }^{8}$. Por otra parte, Dios se presenta, se impone, y no se muestra como un objeto que se ve, sino que entraña una relación, una palabra que hay que comprender. El interés no se centra en el que ve, sino en el que se hace ver. Y se hacen verdaderos esfuerzos de lenguaje para no limitar esta experiencia a una simple percepción visual, y para expresar su carácter existencial y global: se utilizan muchas otras expresiones que tienen más alcance que el verbo ver: encontrarse, presentarse, aparecer ${ }^{9}$. Finalmente hay que decir que el encuentro fue de tal naturaleza que cambió para siempre la vida de los primeros discípulos.

Contrariamente a las experiencias apostólicas, todo lo que hemos descrito son visiones subjetivas, que caracterizan el fenómeno a partir del sujeto que ve o experimenta, obedeciendo totalmente a las leyes psisológico-paranormales, por lo que tienen explicación natural.

Al lado de las percepciones alucinatorias también puede haber verdaderas visiones provocadas, queridas o aceptadas por Dios, pero es preciso fijar un criterio de autenticidad para conocerlas. El criterio no es la intensidad del fenómeno, pues la mente puede producir experiencias realmente espectaculares, como esta en la que se vio una luz tan brillante como el sol:

«Me concentraba en una luz para buscar mejor la presencia de Dios, pero una vez esa luz «explotó» tremendamente, aunque sin sonido, de tal manera que si la hubiera visto materialmente, con los ojos abiertos, me hubiera quedado ciego. Por eso en adelante no me volví a concentrar en la luz».

7. GonzÁlez Quevedo, O., Psicografía, Revista de Parapsicología del CLAP, 11 (1976), p. 14.

8. Léon-Dufour, X., Apariciones de Cristo, Vocabulario de teología bíblica, Barcelona 1982, p. 94.

9. LEon-Dufour, X., Resurrección de Cristo y mensaje pascual, Salamanca 1978, p. 90. 
Tampoco es garantía que se trate de visiones tan bellas que estén más allá de todo lo que se pueda concebir. La siguiente visión celestial no es más que una manifestación del psiquismo inconsciente:

«Un día tuve una visión extraordinariamente bonita y maravillosa. Estaba en estado de concentración y me encontraba muy triste, y entonces vinieron unos personajes con cara de ángeles y me dijeron: «No te asustes, te vamos a llevar a un sitio muy bonito, verás qué feliz eres allí». Me elevaron hacia lo más alto llevándome a otro mundo distinto de éste donde había flores, animales, plantas y gentes como aquí, y las personas eran tan buenas y todo era tan bello y resplandeciente que no tenía ganas de marcharme, pues me sentía feliz como nunca. Me preguntaron si me gustaba estar allí y les dije que sí, que me dejaran, pues no tenía ganas de marchar. Entonces me dijeron: «Te vamos a llevar a tu casa, pero algún día volverás para siempre, pues todavía no ha llegado tu hora ni tu destino». Cuando volví a mi situación normal me sentía muy dichosa y llena, con una alegría que me duró varios días. Me sentía como si algo sobrenatural estuviera en mí, y recordaba aquellos momentos tan maravillosos de tal modo que estuve muchos días iluminada por dentro y por fuera».

La santidad de vida tampoco es criterio seguro, pues cuando un alma se entrega muy intensamente a la oración, con la concentración mental que supone, y está muy dotada en el campo paranormal, automáticamente tendrá un gran número de falsas experiencias místicas. Por todo esto el milagro es de necesidad para la comprobación de la autenticidad de las visiones. La visión siempre es imaginaria y sólo por medio de la prueba del milagro podremos saber si Dios, en una providencia especial, pretendió servirse de la «visión» en cuestión ${ }^{10}$.

\section{LA INTUICIÓN PARANORMAL}

La intuición es la percepción clara, directa, íntima e instantánea de una realidad, tal como si estuviera inmediatamente presente. No necesita de intermediarios mentales, como sucede con el razonamiento discursivo, sino que permite contemplar directamente el objeto.

La mente puede actuar de dos maneras: de modo racional o consciente, y de manera inconsciente. En el conocimiento racional la inteligencia conscientemente forma los conceptos, los juicios y los raciocinios. Pensando, realiza operaciones tales como la comparación, deducción, inducción, análisis y síntesis con las que aumentamos nuestro conocimiento acerca de las cosas. Ahora bien, la mente también puede realizar muchas de estas operaciones de un

10. RAHNER, K., Visiones y profecías, San Sebastián 1956. 
modo inconsciente; por sí misma toma los datos contenidos en su interior tales como los recuerdos de la memoria, las elaboraciones de la razón, las impresiones recibidas, lo que percibe a través de los sentidos físicos y de la percepción extrasensorial, el saber acumulado en el inconsciente colectivo, etc., y los elabora espontáneamente pudiendo llegar a tener manifestaciones intuitivas realmente geniales. Esta tarea se ve impulsada por la concentración mental, pues la detención del pensamiento racional conduce al desarrollo del conocimiento intuitivo.

El conocimiento intuitivo puede ser normal y paranormal. El primero se origina fácilmente en cualquier persona que con frecuencia concentre su mente. El segundo es sólo propio de los grandes dotados, y en él se manifiesta la capacidad de comprensión de la mente en un grado inconmensurable. Siempre se produce en el éxtasis, probablemente en el estado delta, y va acompañado de unos sentimientos de felicidad realmente inenarrables.

La escuela americana de parapsicología ha dividido los fenómenos paranormales en dos grandes grupos: los fenómenos paranormales de efectos psíquicos o de percepción extrasensorial (ESP), llamados también (PG): telepatía, clarividencia y precognición; y los fenómenos paranormales de efectos físicos, o de influencia del psiquismo sobre la materia (PK). Esta clasificación no hace referencia a los fenómenos paranormales de carácter intuitivo que, siendo psíquicos, no coinciden con los de percepción extrasensorial, pero podemos considerar que la intuición paranormal es un fenómeno PG de efectos psíquicos.

Muchos místicos han logrado la intuición paranormal después de una larga dedicación a la concentración mental. Es lo que le sucedió al yogui Pandit Gopi Krishna, quien después de afirmar que estaba concentrado mentalmente en una flor de loto, y que de repente sintió un torrente de luz que penetraba en él como una catarata, añade que la amplitud de su conciencia se hizo inconmensurablemente grande:

«Tenía yo la impresión como de un terremoto cuando, en esto, noté cómo yo mismo me evadía de mi propio cuerpo envuelto en una aureola de luz. Imposible describir al detalle experiencia semejante ... Ya no era yo mismo, o mejor dicho: ya no era yo tal como me conocía a mí mismo, un diminuto punto de percepción recluido dentro de un cuerpo. Se trataba más bien de un círculo de conciencia inconmensurablemente grande allí presente en el que el cuerpo no constituía más que un punto bañado de luz y en unas condiciones de arrobamiento y de felicidad que no son posibles de ser descritas» ${ }^{11}$.

Es relativamente frecuente que esta experiencia aparezca en los dotados

11. ReITER, U., Autorrealización, Bilbao 1977, pp. 9-11. 
que han llegado hasta la muerte clínica, por eso sustentamos la hipótesis de que se produce en el estado delta o de coma. El doctor Raymond A. Moody ha entrevistado a centenares de hombres y de mujeres que estuvieron en el umbral de la muerte y muchos de ellos, en esta situación, tuvieron «visiones de conocimiento» indescriptibles:

«Era como si de repente tuviera conocimiento de todas las cosas, de todo lo que había comenzado desde el principio de los tiempos, de todo lo que seguiría durante toda la eternidad; durante un segundo me pareció conocer todos los secretos de todas las edades, todo el significado del universo, de las estrellas, de la luna... de todo. Pero tras mi decisión de regresar, estos conocimientos se desvanecieron y no recuerdo nada de ellos» ${ }^{12}$.

Frecuentemente este fenómeno PG puede venir acompañado de otro fenómeno $\mathrm{PK}$ en el que el inconsciente actúa sobre el organismo, dando lugar a diversas visiones alucinatorias. Según Raymond A. Moody hay ocasiones en las que se ven extraordinarias «ciudades de luz» con características bíblicas. De este modo las describió una mujer:

«A lo lejos, en la distancia..., pude ver una ciudad. Había edificios, edificios separados unos de otros. Resplandecientes, brillantes. La gente era feliz allí. Había agua centelleante, fuentes...; supongo que habría que describirla como una ciudad de luz... Era maravillosa. Sonaba una música hermosísima. Todo era resplandeciente, maravilloso... Pero creo que si llego a entrar allí no hubiera vuelto nunca... Se me dijo que si iba allí no podría volver..., que la decisión era mía» ${ }^{13}$.

La experiencia es tan maravillosa que ha sido considerada como una prueba de la existencia de «vida después de la vida». En realidad no se trata sino de un fenómeno PG de intuición paranormal sin ninguna transcendencia, sólo sirve para conocer la inmensa capacidad que tiene la mente inconsciente. Puesto que se trata de una inteligencia inconsciente, fácilmente puede llevar al error a toda persona que se deje guiar ciegamente por ella.

La comparación entre la intuición paranormal y las visiones intelectuales que se producen en el arrebatamiento, dentro de la mística experimental cristiana, lleva a la conclusión de que se trata del mismo fenómeno intelectual.

Tanto en la mística oriental como en la cristiana los fenómenos paranormales no se producen en todas las personas. La experiencia enseña que hay algunos que a pesar de su gran diligencia y de las condiciones al parecer favorables,en que practican el zazen, jamás pueden llegar a la iluminación ( = intuición paranormal) ${ }^{14}$. Los orientales lo explican diciendo que se debe al karma desfavorable con que han nacido, consecuencia de las malas acciones de su vi-

12. Moody, R., Reflexiones sobre Vida después de la Vida, Madrid 1981, pp. 32-33.

13. MOODY, R., o.c., pp. 39-40.

14. ENOMiYa-Lassalle, H., o.c., pp. 93-94. 
da anterior, por lo que tienen que reencarnarse hasta que lo consigan; una explicación menos espiritualista es que sólo los dotados experimentan la disociación psíquica causante de estos fenómenos. Por tanto, no es cierto que la experiencia mística oriental sea totalmente debida al uso de ciertas técnicas, como afirman los teólogos cristianos.

\section{LA LEVITACIÓN}

Uno de los fenómenos más admirables de la mística experimental cristiana es la levitación. Como su nombre indica consiste en la elevación espontánea, mantenimiento o desplazamiento en el aire del cuerpo humano sin apoyo alguno y sin causa material visible. Cuando el fenómeno se realiza en los santos afirman los teólogos que tiene un origen claramente sobrenatural, ya que la simple naturaleza no puede alterar las leyes de la gravedad, siempre fijas y constantes ${ }^{15}$. Su importancia radica en que ayuda notablemente a conocer la verdadera naturaleza de la experiencia mística.

Entre los místicos que conocieron el fenómeno extraordinario de la levitación se encuentra santa Teresa. En los arrobamientos había ocasiones en que no sólo el alma, sino que también el cuerpo era llevado por una fuerza extraña hasta levantarle:

«Esto ha sido pocas; porque, como una vez fuese adonde estábamos juntas en el coro, y yendo a comulgar, estando de rodillas, dábame grandísima pena, porque me parecía cosa muy extraordinaria y que había de haber luego mucha nota. Y así mandé a las monjas - porque es ahora después que tengo oficio de priora - no lo dijesen; mas otras veces, como comenzaba a ver que iba a hacer el Señor lo mismo - y una, estando personas principales de señoras, que era la fiesta de la Vocación, en un sermón-, tendíame en el suelo, y allegábanse a tenerme el cuerpo, y todavía se echaba de ver» ${ }^{16}$.

Una de las levitaciones más célebres de santa Teresa fue la que le ocurrió estando con san Juan de la Cruz. Él había venido al convento de la Encarnación para hacer una visita. Mientras san Juan de la Cruz le hablaba de la Santísima Trinidad, fue levantado en el espacio, con la silla en la que estaba sentado. Después, santa Teresa, que estaba de rodillas, también fue levantada del suelo. La hermana Beatriz de Jesús, entrando por azar en la sala, presenció la escena. Asimismo otras hermanas religiosas tuvieron oportunidad de presenciar diversas levitaciones de santa Teresa como consta en el «Acta Authentica

15. Royo MARín, A., Teología de la perfección cristiana, Madrid 1962, p. 875.

16. Vida, 20,5 . 
canonizationis». No cabe duda acerca de la veracidad de los hechos. Ahora bien, ante todo esto hay que aclarar que la levitación no puede presentarse como uno de los milagros exigidos para la beatificación o canonización. Después del proceso sobre el heroísmo de las virtudes, los milagros han de realizarse después de la muerte.

A pesar de lo extraordinario de la levitación no se trata de un milagro, sino de un fenómeno natural. Aunque todavía conocemos muy poco del nuevo mundo de la mente ya sabemos que altera las leyes de la psicología, pudiendo dar lugar a falsas visiones celestiales, y que también altera las leyes físicas hasta el punto de producir la levitación, como se ha podido comprobar en los mediums espiritistas. Se trata de un fenómeno verdaderamente excepcional, de tal modo que los grandes mediums de efectos físicos, D.D. Home, Staiton Moses y Eusapia Paladino raramente consiguieron levitarse. Uno de los más ciertos testimonios acerca de ello lo dio Willian Crookes, descubridor de los rayos catódicos y de elementos químicos como el talio, que llegó a ser presidente de la «Royal Society» inglesa, la sociedad científica más importante de Inglaterra, quien realizó muchas investigaciones entre 1871 y 1874 con D.D. Home. Dice así en su trabajo «Recherches sur le Spiritualisme»:

«Los mejores casos de levitación de Home tuvieron lugar en mi casa. Una vez, entre otras, se colocó en la parte más visible de la sala y, al cabo de un minuto, dijo que se sentía levantado. Vi cómo se elevaba lentamente, con un movimiento continuo y oblicuo, y quedarse durante algunos segundos a seis pulgadas aproximadamente del suelo; en seguida volvió a bajar lentamente. Ninguno de los asistentes se había movido del lugar. El poder de elevarse casi nunca es comunicado a los que están cerca del medium. Sin embargo, una vez, mi esposa fue elevada con el silla en que estaba sentada».

Aunque no se conoce bien el fenómeno de la levitación, parece que la explicación telérgica es una de las que tienen más aceptación. De hecho, si un medium en estado de trance es capaz de levantar una mesa, una silla, un objeto cualquiera, a través de la transformación y exteriorización invisible de su energía somática, que llamamos telergia, también cabe la posibilidad de que sea la telergia la que le levante a sí mismo ${ }^{17}$. Otra posible explicación es admitir que, por determinadas orientaciones de las partículas elementales, el efecto de la atracción de una partícula sobre otra queda anulado, con lo que la gravitación quedaría suprimida por una especie de polarización interna. En tales ocasiones la acción de la mente sobre la materia, alterando las leyes físicas, provocaría estas privilegiadas orientaciones ${ }^{18}$.

17. LoREnZATto, J., Está demostrada la levitación, Revista de Parapsicología del CLAP, 27 (1976), pp. 69-76.

18. TOCQUET, R., La curación por el pensamiento, Barcelona 1975, p. 332. 
En el caso de santa Teresa podemos decir que alcanzó una elevada santidad y una completa madurez humana, pero que al mismo tiempo fue una persona excepcionalmente dotada en el campo paranormal, como lo prueban sus levitaciones. Esto explica el gran número de fenómenos extraordinarios que experimentó, los cuales nada tienen que ver con la verdadera mística.

Podemos concluir diciendo que la mística experimental cristiana no es más que una mítica interpretación de los fenómenos paranormales de la mente: del mismo modo que en la antigüedad se multiplicaron los fenómenos naturales externos, más tarde se mitificaron los fenómenos naturales internos. Las consecuencias de este hecho son incalculables, sobre todo porque esta forma particular de entender la espiritualidad ha estado adornada con los grandes valores bíblicos, y ha sido impulsada por una piedad auténtica y sincera. Por tanto, es preciso y urgente dirigir la espiritualidad. cristiana por un camino más evangélico y objetivo, si se quiere que tenga sentido para el hombre moderno que vive en el mundo de hoy.

Antonio NARRO ROMERO 